\title{
A new modified block iterative algorithm for uniformly quasi- $\varphi$-asymptotically nonexpansive mappings and a system of generalized mixed equilibrium problems
}

Siwaporn Saewan and Poom Kumam*

\footnotetext{
* Correspondence: poom. kum@kmutt.ac.th

Department of Mathematics, Faculty of Science, King Mongkut's University of Technology Thonburi (KMUTT), Bangmod, Bangkok

10140, Thailand
}

\begin{abstract}
In this paper, we introduce a new modified block iterative algorithm for finding a common element of the set of common fixed points of an infinite family of closed and uniformly quasi- $\boldsymbol{\varphi}$-asymptotically nonexpansive mappings, the set of the variational inequality for an $\alpha$-inverse-strongly monotone operator, and the set of solutions of a system of generalized mixed equilibrium problems. We obtain a strong convergence theorem for the sequences generated by this process in a 2-uniformly convex and uniformly smooth Banach space. Our results extend and improve ones from several earlier works.

2000 MSC: 47H05; 47H09; 47H10.

Keywords: modified block iterative algorithm, inverse-strongly monotone operator, variational inequality, a system of generalized mixed equilibrium problem, uniformly quasi- $\varphi$-asymptotically nonexpansive mapping
\end{abstract}

\section{Introduction}

Let $C$ be a nonempty closed convex subset of a real Banach space $E$ with $\|\cdot\|$ and let $E^{*}$ be the dual space of $E$. Let $\left\{f_{i}\right\}_{i \in \Gamma}: C \times C \rightarrow \mathbb{R}$ be a bifunction, $\left\{\phi_{i}\right\}_{i \in \Gamma}: C \rightarrow \mathbb{R}$ be a real-valued function, and $\left\{B_{i}\right\}_{i \in \Gamma}: C \rightarrow E^{*}$ be a monotone mapping, where $\Gamma$ is an arbitrary index set. The system of generalized mixed equilibrium problems is to find $x \in C$ such that

$$
f_{i}(x, y)+\left\langle B_{i} x, y-x\right\rangle+\varphi_{i}(y)-\varphi_{i}(x) \geq 0, \quad i \in \Gamma, \forall y \in C
$$

If $\Gamma$ is a singleton, then problem (1.1) reduces to the generalized mixed equilibrium problem, which is to find $x \in C$ such that

$$
f(x, y)+\langle B x, y-x\rangle+\varphi(y)-\varphi(x) \geq 0, \quad \forall y \in C .
$$

The set of solutions to (1.2) is denoted by $\operatorname{GMEP}(f, B, \phi)$, i.e.,

$$
\operatorname{GMEP}(f, B, \varphi)=\{x \in C: f(x, y)+\langle B x, y-x\rangle+\varphi(y)-\varphi(x) \geq 0, \forall y \in C\} .
$$


If $B \equiv 0$, the problem (1.2) reduces into the mixed equilibrium problem for $f$, denoted by $\operatorname{MEP}(f, \phi)$, which is to find $x \in C$ such that

$$
f(x, y)+\varphi(y)-\varphi(x) \geq 0, \quad \forall y \in C .
$$

If $f \equiv 0$, the problem (1.2) reduces into the mixed variational inequality of Browder type, denoted by $\operatorname{VI}(C, B, \phi)$, which is to find $x \in C$ such that

$$
\langle B x, y-x\rangle+\varphi(y)-\varphi(x) \geq 0, \quad \forall y \in C .
$$

If $B \equiv 0$ and $\phi \equiv 0$ the problem (1.2) reduces into the equilibrium problem for $f$, denoted by $\operatorname{EP}(f)$, which is to find $x \in C$ such that

$$
f(x, y) \geq 0, \quad \forall y \in C .
$$

If $f \equiv 0$, the problem (1.4) reduces into the minimize problem, denoted by $\operatorname{Argmin}(\phi)$, which is to find $x \in C$ such that

$$
\varphi(y)-\varphi(x) \geq 0, \quad \forall y \in C .
$$

The above formulation (1.5) was shown in [1] to cover monotone inclusion problems, saddle point problems, variational inequality problems, minimization problems, optimization problems, vector equilibrium problems, Nash equilibria in noncooperative games. In addition, there are several other problems, for example, the complementarity problem, fixed point problem and optimization problem, which can also be written in the form of an $\operatorname{EP}(f)$. In other words, the $\operatorname{EP}(f)$ is an unifying model for several problems arising in physics, engineering, science, optimization, economics, etc. In the last two decades, many papers have appeared in the literature on the existence of solutions of $\operatorname{EP}(f)$; see, for example [1,2] and references therein. Some solution methods have been proposed to solve the $\mathrm{EP}(f)$; see, for example, [1-15] and references therein.

The normalized duality mapping $J: E \rightarrow 2^{E_{* *}}$ is defined by

$$
J(x)=\left\{x^{*} \in E^{*}:\left\langle x, x^{*}\right\rangle=\|x\|^{2},\left\|x^{*}\right\|=\|x\|\right\}
$$

for all $x \in E$. If $E$ is a Hilbert space, then $J=I$, where $I$ is the identity mapping. Consider the functional defined by

$$
\phi(x, y)=\|x\|^{2}-2\langle x, J y\rangle+\|y\|^{2}, \quad \forall x, y \in E .
$$

As well known that if $C$ is a nonempty closed convex subset of a Hilbert space $H$ and $P_{C}: H \rightarrow C$ is the metric projection of $H$ onto $C$, then $P_{C}$ is nonexpansive. This fact actually characterizes Hilbert spaces and consequently, it is not available in more general Banach spaces. It is obvious from the definition of function $\varphi$ that

$$
(\|x\|-\|y\|)^{2} \leq \phi(x, y) \leq(\|x\|+\|y\|)^{2}, \quad \forall x, y \in E .
$$

If $E$ is a Hilbert space, then $\varphi(x, y)=\|x-y\|^{2}$, for all $x, y \in E$. On the other hand, the generalized projection [16] $\Pi_{C}: E \rightarrow C$ is a map that assigns to an arbitrary point $x$ $\in E$ the minimum point of the functional $\varphi(x, y)$, that is, $\Pi_{C} x=\bar{x}$, where $\bar{x}$ is the solution to the minimization problem

$$
\phi(\bar{x}, x)=\inf _{y \in C} \phi(y, x),
$$


existence and uniqueness of the operator $\Pi_{C}$ follows from the properties of the functional $\varphi(x, y)$ and strict monotonicity of the mapping $J$ (see, for example, [16-20]).

Remark 1.1. If $E$ is a reflexive, strictly convex, and smooth Banach space, then for $x$, $y \in E, \varphi(x, y)=0$ if and only if $x=y$. It is sufficient to show that if $\varphi(x, y)=0$ then $x$ $=y$. From (1.8), we have $\|x\|=\|y\|$. This implies that $\langle x, J y\rangle=\|x\|^{2}=\|J y\|^{2}$. From the definition of $J$, one has $J x=J y$. Therefore, we have $x=y$; see $[18,20]$ for more details.

Let $C$ be a closed convex subset of $E$, a mapping $T: C \rightarrow C$ is said to be L-Lipschitz continuous if $\|T x-T y\| \leq L\|x-y\|, \forall x, y \in C$ and a mapping $T$ is said to be nonexpansive if $\|T x-T y\| \leq\|x-y\|, \forall x, y \in C$. A point $x \in C$ is a fixed point of $T$ provided $T x=x$. Denote by $F(T)$ the set of fixed points of $T$; that is, $F(T)=\{x \in C: T x=$ $x\}$. Recall that a point $p$ in $C$ is said to be an asymptotic fixed point of $T$ [21] if $C$ contains a sequence $\left\{x_{n}\right\}$ which converges weakly to $p$ such that $\lim _{n \rightarrow \infty}|| x_{n}-T x_{n} \|=0$. The set of asymptotic fixed points of $T$ will be denoted by $\widetilde{F(T)}$.

A mapping $T$ from $C$ into itself is said to be relatively nonexpansive [22-24] if $\widetilde{F(T)}=F(T)$ and $\varphi(p, T x) \leq \varphi(p, x)$ for all $x \in C$ and $p \in F(T)$. $T$ is said to be relatively quasi-nonexpansive if $F(T) \neq \varnothing$ and $\varphi(p, T x) \leq \varphi(p, x)$ for all $x \in C$ and $p \in F(T)$. T is said to be $\varphi$-nonexpansive, if $\varphi(T x, T y) \leq \varphi(x, y)$ for $x, y \in C$. $T$ is said to be quasi- $\varphi$ asymptotically nonexpansive if $F(T) \neq \varnothing$ and there exists a real sequence $\left\{k_{n}\right\} \subset[1, \infty)$ with $k_{n} \rightarrow 1$ such that $\varphi\left(p, T^{n} x\right) \leq k_{n} \varphi(p, x)$ for all $n \geq 1 x \in C$ and $p \in F(T)$. The asymptotic behavior of a relatively nonexpansive mapping was studied in [25-27].

We note that the class of relatively quasi-nonexpansive mappings is more general than the class of relatively nonexpansive mappings [25-29] which requires the strong restriction: $F(T)=\widetilde{F(T)}$. A mapping $T$ is said to be closed if for any sequence $\left\{x_{n}\right\} \subset C$ with $x_{n} \rightarrow x$ and $T x_{n} \rightarrow y$, then $T x=y$. It is easy to know that each relatively nonexpansive mapping is closed.

Definition 1.2. (Chang et al. [30]) (1) Let $\left\{T_{i}\right\}_{i=1}^{\infty}: C \rightarrow C$ be a sequence of mapping. $\left\{T_{i}\right\}_{i=1}^{\infty}$ is said to be a family of uniformly quasi- $\varphi$-asymptotically nonexpansive mappings, if $\mathcal{F}:=\cap_{i=1}^{\infty} F\left(T_{i}\right) \neq \emptyset$, and there exists a sequence $\left\{k_{n}\right\} \subset[1, \infty)$ with $k_{n} \rightarrow 1$ such that for each $i \geq 1$

$$
\phi\left(p, T_{i}^{n} x\right) \leq k_{n} \phi(p, x), \quad \forall p \in \mathcal{F}, x \in C, \forall n \geq 1 .
$$

(2) A mapping $T: C \rightarrow C$ is said to be uniformly L-Lipschitz continuous, if there exists a constant $L>0$ such that

$$
\left\|T^{n} x-T^{n} y\right\| \leq L\|x-y\|, \quad \forall x, y \in C .
$$

Recall that let $A: C \rightarrow E^{*}$ be a mapping. Then $A$ is called

(i) monotone if

$$
\langle A x-A y, x-y\rangle \geq 0, \quad \forall x, y \in C,
$$

(ii) $\alpha$-inverse-strongly monotone if there exists a constant $\alpha>0$ such that

$$
\langle A x-A y, x-y\rangle \geq \alpha\|A x-A y\|^{2}, \quad \forall x, y \in C .
$$

Remark 1.3. It is easy to see that an $\alpha$-inverse-strongly monotone is monotone and $\frac{1}{\alpha}$-Lipschitz continuous. 
In 2004, Matsushita and Takahashi [31] introduced the following iteration: a sequence $\left\{x_{n}\right\}$ defined by

$$
x_{n+1}=\Pi_{C} J^{-1}\left(\alpha_{n} J x_{n}+\left(1-\alpha_{n}\right) J T x_{n}\right),
$$

where the initial guess element $x_{0} \in C$ is arbitrary, $\left\{\alpha_{n}\right\}$ is a real sequence in $[0,1], T$ is a relatively nonexpansive mapping and $\Pi_{C}$ denotes the generalized projection from $E$ onto a closed convex subset $C$ of $E$. They proved that the sequence $\left\{x_{n}\right\}$ converges weakly to a fixed point of $T$.

In 2005, Matsushita and Takahashi [28] proposed the following hybrid iteration method (it is also called the CQ method) with generalized projection for relatively nonexpansive mapping $T$ in a Banach space $E$ :

$$
\left\{\begin{array}{l}
x_{0} \in C \text { chosen arbitrarily, } \\
y_{n}=J^{-1}\left(\alpha_{n} J x_{n}+\left(1-\alpha_{n}\right) J T x_{n}\right), \\
C_{n}=\left\{z \in C: \phi\left(z, y_{n}\right) \leq \phi\left(z, x_{n}\right)\right\} \\
Q_{n}=\left\{z \in C:\left\langle x_{n}-z, J x_{0}-J x_{n}\right\rangle \geq 0\right\} \\
x_{n+1}=\Pi_{C_{n} \cap Q_{n}} x_{0} .
\end{array}\right.
$$

They proved that $\left\{x_{n}\right\}$ converges strongly to $\Pi_{F(T)} x_{0}$, where $\Pi_{F(T)}$ is the generalized projection from $C$ onto $F(T)$.

In 2008, Iiduka and Takahashi [32] introduced the following iterative scheme for finding a solution of the variational inequality problem for an inverse-strongly monotone operator $A$ in a 2-uniformly convex and uniformly smooth Banach space $E: x_{1}=$ $x \in C$ and

$$
x_{n+1}=\Pi_{C} J^{-1}\left(J x_{n}-\lambda_{n} A x_{n}\right),
$$

for every $n=1,2,3, \ldots$, where $\Pi_{C}$ is the generalized metric projection from $E$ onto $C$, $J$ is the duality mapping from $E$ into $E^{*}$ and $\left\{\lambda_{n}\right\}$ is a sequence of positive real numbers. They proved that the sequence $\left\{x_{n}\right\}$ generated by (1.15) converges weakly to some element of $\mathrm{VI}(A, C)$. Takahashi and Zembayashi [33,34] studied the problem of finding a common element of the set of fixed points of a nonexpansive mapping and the set of solutions of an equilibrium problem in the framework of Banach spaces.

In 2009, Wattanawitoon and Kumam [14] using the idea of Takahashi and Zembayashi [33] extended the notion from relatively nonexpansive mappings or $\varphi$-nonexpansive mappings to two relatively quasi-nonexpansive mappings and also proved some strong convergence theorems to approximate a common fixed point of relatively quasi-nonexpansive mappings and the set of solutions of an equilibrium problem in the framework of Banach spaces. Cholamjiak [35] studied the following iterative algorithm:

$$
\left\{\begin{array}{l}
z_{n}=\Pi_{C} J^{-1}\left(J x_{n}-\lambda_{n} A x_{n}\right), \\
y_{n}=J^{-1}\left(\alpha_{n} J x_{n}+\beta_{n} J T x_{n}+\gamma_{n} J S z_{n}\right), \\
u_{n} \in C \text { such that } f\left(u_{n}, y\right)+\frac{1}{r_{n}}\left\langle y-u_{n}, J u_{n}-J y_{n}\right\rangle \geq 0, \quad \forall y \in C, \\
C_{n+1}=\left\{z \in C_{n}: \phi\left(z, u_{n}\right) \leq \phi\left(z, x_{n}\right)\right\}, \\
x_{n+1}=\Pi_{C_{n+1}} x_{0},
\end{array}\right.
$$

where $J$ is the duality mapping on $E$. Assume that $\left\{\alpha_{n}\right\},\left\{\beta_{n}\right\}$ and $\left\{\gamma_{n}\right\}$ are sequences in $[0,1]$. Then, he proved that $\left\{x_{n}\right\}$ converges strongly to $q=\Pi_{F} x_{0}$, where $F:=F(T) \cap F$ $(S) \cap \operatorname{EP}(f) \cap \operatorname{VI}(A, C)$. 
In 2010, Saewan et al. [29] introduced a new hybrid projection iterative scheme which is difference from the algorithm (1.16) of Cholamjiak in [[35], Theorem 3.1] for two relatively quasi-nonexpansive mappings in a Banach space. Motivated by the results of Takahashi and Zembayashi [34], Cholumjiak and Suantai [36] proved the following strong convergence theorem by the hybrid iterative scheme for approximation of common fixed point of countable families of relatively quasi-nonexpansive mappings in a uniformly convex and uniformly smooth Banach space: $x_{0} \in E, x_{1}=\Pi_{C_{1}} x_{0}, C_{1}=C$

$$
\left\{\begin{array}{l}
y_{n, i}=J^{-1}\left(\alpha_{n} J x_{n}+\left(1-\alpha_{n}\right) J T x_{n}\right) \\
u_{n, i}=T_{r_{m, n}}^{f_{m}} T_{r_{m-1, n}^{m}}^{f_{m-1}} \cdots T_{r_{1, n}}^{f_{1}} y_{n, i} \\
C_{n+1}=\left\{z \in C_{n}: \sup _{i>1} \phi\left(z, J u_{n, i}\right) \leq \phi\left(w_{,} J x_{n}\right)\right\} \\
x_{n+1}=\prod_{C_{n+1}} x_{0}, n \geq 1
\end{array}\right.
$$

Then, they proved that under certain appropriate conditions imposed on $\left\{\alpha_{n}\right\}$, and $\left\{r_{n}, i\right\}$, the sequence $\left\{x_{n}\right\}$ converges strongly to $\Pi_{F(T) \cap E \mathrm{P}(f)} x_{0}$.

We note that the block iterative method is a method which often used by many authors to solve the convex feasibility problem (see, [37,38], etc.). In 2008, Plubtieng and Ungchittrakool [39] established strong convergence theorems of block iterative methods for a finite family of relatively nonexpansive mappings in a Banach space by using the hybrid method in mathematical programming. Chang et al. [30] proposed the modified block iterative algorithm for solving the convex feasibility problems for an infinite family of closed and uniformly quasi- $\varphi$-asymptotically nonexpansive mapping, and they obtained the strong convergence theorems in a Banach space.

In 2010, Saewan and Kumam [40] obtained the following result for the set of solutions of the generalized equilibrium problems and the set of common fixed points of an infinite family of closed and uniformly quasi- $\varphi$-asymptotically nonexpansive mappings in a uniformly smooth and strictly convex Banach space $E$ with Kadec-Klee property.

Theorem SK Let $C$ be a nonempty closed and convex subset of a uniformly smooth and strictly convex Banach space $E$ with the Kadec-Klee property. Let $f$ be a bifunction from $C \times C$ to $\mathbb{R}$ satisfying (A1)-(A4). Let $B$ be a continuous monotone mapping of $C$ into $E^{*}$. Let $\left\{S_{i}\right\}_{i=1}^{\infty}: C \rightarrow C$ be an infinite family of closed uniformly $L_{i}$-Lipschitz continuous and uniformly quasi- $\varphi$-asymptotically nonexpansive mappings with a sequence $\left\{k_{n}\right\} \subset[1, \infty), k_{n} \rightarrow 1$ such that $F:=\cap_{i=1}^{\infty} F\left(S_{i}\right) \cap \operatorname{GEP}(f, B)$ is a nonempty and bounded subset in $C$. For an initial point $x_{0} \in E$ with $x_{1}=\Pi_{C_{1}} x_{0}$ and $C_{1}=C$, we define the sequence $\left\{x_{n}\right\}$ as follows:

$$
\left\{\begin{array}{l}
y_{n}=J^{-1}\left(\beta_{n} J x_{n}+\left(1-\beta_{n}\right) J z_{n}\right), \\
z_{n}=J^{-1}\left(\alpha_{n, 0} J x_{n}+\sum_{i=1}^{\infty} \alpha_{n, j} J S_{i}^{n} x_{n}\right), \\
u_{n} \in C \text { such that } f\left(u_{n}, \gamma\right)+\left\langle B y_{n}, y-u_{n}\right\rangle+\frac{1}{r_{n}}\left\langle y-u_{n}, J u_{n}-J y_{n}\right\rangle \geq 0, \quad \forall y \in C, \\
C_{n+1}=\left\{z \in C_{n}: \phi\left(z, u_{n}\right) \leq \phi\left(z, x_{n}\right)+\theta_{n}\right\}_{,} \\
x_{n+1}=\Pi_{C_{n+1}} x_{0}, \quad \forall n \geq 0,
\end{array}\right.
$$

where $J$ is the duality mapping on $E, \theta_{n}=\sup _{q \in F}\left(k_{n}-1\right) \varphi\left(q, x_{n}\right),\left\{\alpha_{n}, i\right\},\left\{\beta_{n}\right\}$ are sequences in $[0,1]$ and $\left\{r_{n}\right\} \subset[a, \infty)$ for some $a>0$. If $\sum_{i=0}^{\infty} \alpha_{n, i}=1$ for all $n \geq 0$ and $\lim \inf _{n \rightarrow \infty} \alpha_{n, 0} \alpha_{n, i}>0$ for all $i \geq 1$, then $\left\{x_{n}\right\}$ converges strongly to $p \in F$, where $p=\Pi_{F} x_{0}$. 
Quite recently, Qin et al. [9] purposed the problem of approximating a common fixed point of two asymptotically quasi- $\varphi$-nonexpansive mappings based on hybrid projection methods. Strong convergence theorems are established in a real Banach space. Zegeye et al. [15] introduced an iterative process which converges strongly to a common element of set of common fixed points of countably infinite family of closed relatively quasi- nonexpansive mappings, the solution set of generalized equilibrium problem and the solution set of the variational inequality problem for an $\alpha$-inverse-strongly monotone mapping in Banach spaces.

Motivated and inspired by the work of Chang et al. [30], Qin et al. [7], Takahashi and Zembayashi [33], Wattanawitoon and Kumam [14], Zegeye [41] and Saewan and Kumam [40], we introduce a new modified block hybrid projection algorithm for finding a common element of the set of the variational inequality for an $\alpha$-inverse-strongly monotone operator, the set of solutions of the system of generalized mixed equilibrium problems and the set of common fixed points of an infinite family of closed and uniformly quasi- $\varphi$-asymptotically nonexpansive mappings in the framework Banach spaces. The results presented in this paper improve and generalize some well-known results in the literature.

\section{Preliminaries}

A Banach space $E$ is said to be strictly convex if $\left\|\frac{x+y}{2}\right\|<1$ for all $x, y \in E$ with $\|x\|=$ $\|y\|=1$ and $x \neq y$. Let $U=\{x \in E:\|x\|=1\}$ be the unit sphere of $E$. Then a Banach space $E$ is said to be smooth if the limit

$$
\lim _{t \rightarrow 0} \frac{\|x+t y\|-\|x\|}{t}
$$

exists for each $x, y \in U$. It is also said to be uniformly smooth if the limit is attained uniformly for $x, y \in U$. Let $E$ be a Banach space. The modulus of convexity of $E$ is the function $\delta:[0,2] \rightarrow[0,1]$ defined by

$$
\delta(\varepsilon)=\inf \left\{1-\left\|\frac{x+y}{2}\right\|: x, y \in E,\|x\|=\|y\|=1,\|x-y\| \geq \varepsilon\right\} .
$$

A Banach space $E$ is uniformly convex if and only if $\delta(\varepsilon)>0$ for all $\varepsilon \in(0,2]$. Let $p$ be a fixed real number with $p \geq 2$. A Banach space $E$ is said to be $p$-uniformly convex if there exists a constant $c>0$ such that $\delta(\varepsilon) \geq c \varepsilon^{p}$ for all $\varepsilon \in[0,2]$; see [42,43] for more details. Observe that every $p$-uniformly convex is uniformly convex. One should note that no a Banach space is $p$-uniformly convex for $1<p<2$. It is well known that a Hilbert space is 2-uniformly convex, uniformly smooth. It is also known that if $E$ is uniformly smooth, then $J$ is uniformly norm-to-norm continuous on each bounded subset of $E$.

Remark 2.1. The following basic properties can be found in Cioranescu [18].

(i) If $E$ is a uniformly smooth Banach space, then $J$ is uniformly continuous on each bounded subset of $E$.

(ii) If $E$ is a smooth, strictly convex, and reflexive Banach space, then the normalized duality mapping $J: E \rightarrow 2^{E_{*}}$ is single-valued, one-to-one, and onto.

(iii) A Banach space $E$ is uniformly smooth if and only if $E^{*}$ is uniformly convex.

(iv) Each uniformly convex Banach space $E$ has the Kadec-Klee property, that is, for any sequence $\left\{x_{n}\right\} \subset E$, if $x_{n} \rightarrow x \in E$ and $\left\|x_{n}\right\| \rightarrow\|x\|$, then $x_{n} \rightarrow x$. 
We also need the following lemmas for the proof of our main results.

Lemma 2.2. (Beauzamy [44] and Xu [45]). If E be a 2-uniformly convex Banach space, then for all $x, y \in E$ we have

$$
\|x-y\| \leq \frac{2}{c^{2}}\|J x-J y\|,
$$

where $J$ is the normalized duality mapping of $E$ and $0<c \leq 1$.

The best constant $\frac{1}{c}$ in lemma is called the p-uniformly convex constant of $E$.

Lemma 2.3. (Beauzamy [44] and Zalinescu [46]). If E be a p-uniformly convex Banach space and let $p$ be a given real number with $p \geq 2$, then for all $x, y \in E, j_{x} \in J_{p}$ $(x)$ and $j_{y} \in J_{p}(y)$

$$
\left\langle x-y_{1} j_{x}-j_{y}\right\rangle \geq \frac{c^{p}}{2^{p-2} p}\|x-y\|^{p},
$$

where $J_{p}$ is the generalized duality mapping of $E$ and $\frac{1}{c}$ is the p-uniformly convexity constant of $E$.

Lemma 2.4. (Kamimura and Takahashi [19]). Let E be a uniformly convex and smooth Banach space and let $\left\{x_{n}\right\}$ and $\left\{y_{n}\right\}$ be two sequences of $E$. If $\varphi\left(x_{n}, y_{n}\right) \rightarrow 0$ and either $\left\{x_{n}\right\}$ or $\left\{y_{n}\right\}$ is bounded, then $\left\|x_{n}-y_{n}\right\| \rightarrow 0$.

Lemma 2.5. (Alber [16]). Let $C$ be a nonempty closed convex subset of a smooth Banach space and $x \in E$. Then $x_{0}=\Pi_{C} x$ if and only if

$$
\left\langle x_{0}-y, J x-J x_{0}\right\rangle \geq 0, \quad \forall y \in C .
$$

Lemma 2.6. (Alber [[16], Lemma 2.4]). Let E be a reflexive, strictly convex and smooth Banach space, and let $C$ be a nonempty closed convex subset of $E$ and let $x \in$ E. Then

$$
\phi\left(y, \Pi_{C} x\right)+\phi\left(\Pi_{C} x, x\right) \leq \phi(y, x), \quad \forall y \in C .
$$

Let $E$ be a reflexive, strictly convex, smooth Banach space and $J$ is the duality mapping from $E$ into $E^{*}$. Then $J^{-1}$ is also single value, one-to-one, surjective, and it is the duality mapping from $E^{*}$ into $E$. We make use of the following mapping $V$ studied in Alber [16]:

$$
V\left(x, x^{*}\right)=\|x\|^{2}-2\left\langle x, x^{*}\right\rangle+\left\|x^{*}\right\|^{2},
$$

for all $x \in E$ and $x^{*} \in E^{*}$, that is, $V\left(x, x^{*}\right)=\varphi\left(x, J^{1}\left(x^{*}\right)\right)$.

Lemma 2.7. (Alber [16]). Let E be a reflexive, strictly convex smooth Banach space and let $V$ be as in (2.1). Then

$$
V\left(x, x^{*}\right)+2\left\langle J^{-1}\left(x^{*}\right)-x, y^{*}\right\rangle \leq V\left(x, x^{*}+y^{*}\right),
$$

for all $x \in E$ and $x^{*}, y^{*} \in E^{*}$.

A set valued mapping $U: E \rightrightarrows E^{*}$ with graph $\left.G(U)=\left(x, x^{*}\right): x^{*} \in U x\right\}$, domain $D(U)$ $=\{x \in E: U x \neq \varnothing\}$, and range $R(U)=\mathrm{U}\{U x: x \in D(U)\}$. $U$ is said to be monotone if $\langle x$ - $\left.y, x^{*}-y^{*}\right\rangle \geq 0$ whenever $\left(x, x^{*}\right) \in G(U),\left(y, y^{*}\right) \in G(U)$. We denote a set valued operator $U$ from $E$ to $E^{*}$ by $U \subset E \times E^{*}$. A monotone $U$ is said to be maximal if its graph is not property contained in the graph of any other monotone operator. If $U$ is maximal monotone, then the solution set $U^{-1} 0$ is closed and convex. Let $E$ be a reflexive, strictly 
convex and smooth Banach space, and it is known that $U$ is a maximal monotone if and only if $R(J+r U)=E^{*}$ for all $r>0$. Define the resolvent of $U$ by $J_{r} x=x_{r}$. In other words, $J r=(J+r \mathrm{U})^{-1}$ for all $r>0$. $J_{r}$ is a single-valued mapping from $E$ to $D(U)$. Also, $U^{-1}(0)=F\left(J_{r}\right)$ for all $r>0$, where $F\left(J_{r}\right)$ is the set of all fixed points of $J r$. Define, for $r$ $>0$, the Yosida approximation of $U$ by $T_{r} x=\left(J x-J J_{r} x\right) / r$ for all $x \in C$ : We know that $T_{r} x \in U\left(J_{r} x\right)$ for all $r>0$ and $x \in E$.

Let $A$ be an inverse-strongly monotone mapping of $C$ into $E^{*}$ which is said to be hemicontinuous if for all $x, y \in C$, and the mapping $F$ of $[0,1]$ into $E^{*}$, defined by $F(t)$ $=A(t x+(1-t) y)$, is continuous with respect to the weak" topology of $E^{*}$. We define by $N_{C}(v)$ the normal cone for $C$ at a point $v \in C$, that is,

$$
N_{C}(v)=\left\{x^{*} \in E^{*}:\left\langle v-y, x^{*}\right\rangle \geq 0, \forall y \in C\right\} .
$$

Lemma 2.8. (Rockafellar [47]). Let $C$ be a nonempty, closed convex subset of a Banach space $E$, and $A$ is a monotone, hemicontinuous operator of $C$ into $E^{*}$. Let $U \subset$ $E \times E^{*}$ be an operator defined as follows:

$$
U v= \begin{cases}A v+N_{C}(v), & v \in C \\ \emptyset & \text { otherwise. }\end{cases}
$$

Then $U$ is maximal monotone and $U^{-1} 0=V I(A, C)$.

Lemma 2.9. (Chang et al. [30]). Let $E$ be a uniformly convex Banach space, $r>0$ be a positive number and $B_{r}(0)$ be a closed ball of $E$. Then, for any given sequence $\left\{x_{i}\right\}_{i=1}^{\infty} \subset B_{r}(0)$ and for any given sequence $\left\{\lambda_{i}\right\}_{i=1}^{\infty}$ of positive number with $\sum_{n=1}^{\infty} \lambda_{n}=1$, there exists a continuous, strictly increasing, and convex function $g:[0,2 r) \rightarrow[0, \infty)$ with $g(0)=0$ such that, for any positive integer $i, j$ with $i<j$,

$$
\left\|\sum_{n=1}^{\infty} \lambda_{n} x_{n}\right\|^{2} \leq \sum_{n=1}^{\infty} \lambda_{n}\left\|x_{n}\right\|^{2}-\lambda_{i} \lambda_{j} g\left(\left\|x_{i}-x_{j}\right\|\right) .
$$

Lemma 2.10. (Chang et al. [30]). Let E be a real uniformly smooth and strictly convex Banach space, and $C$ be a nonempty closed convex subset of $E$. Let $T: C \rightarrow C$ be a closed and quasi- $\varphi$-asymptotically nonexpansive mapping with a sequence $\left\{k_{n}\right\} \subset[1, \infty)$, $k_{n} \rightarrow 1$. Then $F(T)$ is a closed convex subset of $C$ :

For solving the equilibrium problem for a bifunction $f: C \times C \rightarrow \mathbb{R}$, let us assume that $f$ satisfies the following conditions:

(A1) $f(x, x)=0$ for all $x \in C$;

(A2) $f$ is monotone, i.e., $f(x, y)+f(y, x) \leq 0$ for all $x, y \in C$;

(A3) for each $x, y, z \in C$,

$$
\lim _{t \downarrow 0} f(t z+(1-t) x, y) \leq f(x, y)
$$

(A4) for each $x \in C, y \propto f(x, y)$ is convex and lower semicontinuous.

For example, let $A$ be a continuous and monotone operator of $C$ into $E^{*}$ and define

$$
f(x, y)=\langle A x, y-x\rangle, \quad \forall x, y \in C .
$$

Then, $f$ satisfies (A1)-(A4). The following result is in Blum and Oettli [1].

Motivated by Combettes and Hirstoaga [2] in a Hilbert space and Takahashi and Zembayashi [33] in a Banach space, Zhang [48] obtained the following lemma. 
Lemma 2.11. (Zhang [[48], Lemma 1.5]). Let $C$ be a closed convex subset of a smooth, strictly convex and reflexive Banach space E. Assume that $f$ be a bifunction from $C \times C$ to $\mathbb{R}$ satisfying (A1)-(A4), $A: C \rightarrow E^{*}$ be a continuous and monotone mapping and $\phi: C \rightarrow \mathbb{R}$ be a semicontinuous and convex functional. For $r>0$ and let $x \in$ E. Then, there exists $z \in C$ such that

$$
Q(z, y)+\frac{1}{r}\langle y-z, J z-J x\rangle \geq 0, \quad \forall y \in C,
$$

where $Q(z, y)=f(z, y)+\langle B z, y-z\rangle+\phi(y) \phi(z), x, y \in C$. Furthermore, define a mapping $T_{r}: E \rightarrow C$ as follows:

$$
T_{r} x=\left\{z \in C: Q(z, y)+\frac{1}{r}\langle y-z, J z-J x\rangle \geq 0, \forall y \in C\right\} .
$$

Then the following hold:

1. $T_{r}$ is single-valued;

2. $T_{r}$ is firmly nonexpansive, i.e., for all $x, y \in E,\left\langle T_{r} x-T_{r} y, J T_{r} x-J T_{r} y\right\rangle \leq\left\langle T_{r} x-\right.$

$\left.T_{r} y, J x-J y\right\rangle$;

3. $F\left(T_{r}\right)=\widetilde{F\left(T_{r}\right)}=\operatorname{GMEP}(f, B, \varphi)$;

4. $\operatorname{GMEP}(f, B, \phi)$ is closed and convex;

5. $\varphi\left(p, T_{r} z\right)+\varphi\left(T_{r} z, z\right) \leq \varphi(p, z), \forall p \in F\left(T_{r}\right)$ and $z \in E$.

\section{Main results}

In this section, we prove the new convergence theorems for finding the set of solutions of system of generalized mixed equilibrium problems, the common fixed point set of a family of closed and uniformly quasi- $\varphi$-asymptotically nonexpansive mappings, and the solution set of variational inequalities for an $\alpha$-inverse strongly monotone mapping in a 2-uniformly convex and uniformly smooth Banach space.

Theorem 3.1. Let $C$ be a nonempty closed and convex subset of a 2-uniformly convex and uniformly smooth Banach space $E$. For each $j=1,2, \ldots, m$ let $f_{j}$ be a bifunction from $C$ $\times C$ to $\mathbb{R}$ which satisfies conditions (A1)-(A4), $B_{j}: C \rightarrow E^{*}$ be a continuous and monotone mapping and $\phi_{j}: C i \rightarrow \mathbb{R}$ be a lower semicontinuous and convex function. Let $A$ be an $\alpha$ inverse-strongly monotone mapping of $C$ into $E^{*}$ satisfying $\|A y\| \leq\|A y-A u\|, \forall y \in C$ and $u \in V I(A, C) \neq \varnothing$. Let $\left\{S_{i}\right\}_{i=1}^{\infty}: C \rightarrow$ Cbe an infinite family of closed uniformly $L_{i}$-Lipschitz continuous and uniformly quasi- $\varphi$-asymptotically nonexpansive mappings with a sequence $\left\{k_{n}\right\} \subset[1, \infty), k_{n} \rightarrow 1$ such that $F:=\left(\cap_{i=1}^{\infty} F\left(S_{i}\right)\right) \cap\left(\cap_{j=1}^{m} \operatorname{GMEP}\left(f_{j}, B_{j}, \varphi_{j}\right)\right)(\cap \mathrm{VI}(A, C))$ is a nonempty and bounded subset in $C$. For an initial point $x_{0} \in E$ with $x_{1}=\Pi_{C_{1}} x_{0}$ and $C_{1}=$ $C$, we define the sequence $\left\{x_{n}\right\}$ as follows:

$$
\left\{\begin{array}{l}
v_{n}=\Pi_{C} J^{-1}\left(J x_{n}-\lambda_{n} A x_{n}\right), \\
z_{n}=J^{-1}\left(\alpha_{n, 0} J x_{n}+\sum_{i=1}^{\infty} \alpha_{n, i} J S_{i}^{n} v_{n}\right), \\
y_{n}=J^{-1}\left(\beta_{n} J x_{n}+\left(1-\beta_{n}\right) J z_{n}\right), \\
u_{n}=T_{r_{m, n}}^{Q_{m}} T_{r_{m-1, n}}^{Q_{m-1}} \cdots T_{r_{2}, n}^{Q_{2}} T_{r_{1, n}}^{Q_{1}} y_{n}, \\
C_{n+1}=\left\{z \in C_{n}: \phi\left(z, u_{n}\right) \leq \phi\left(z, x_{n}\right)+\theta_{n}\right\}, \\
x_{n+1}=\Pi_{C_{n+1}} x_{0}, \quad \forall n \geq 1,
\end{array}\right.
$$

where $\theta_{n}=\sup _{q \in F}\left(k_{n}-1\right) \varphi\left(q, x_{n}\right)$, for each $i \geq 0,\left\{\alpha_{n}, i\right\}$ and $\left\{\beta_{n}\right\}$ are sequences in $[0,1]$, $\left\{r_{j}, n\right\} \subset[d, \infty)$ for some $d>0$ and $\left\{\lambda_{n}\right\} \subset[a, b]$ for some $a, b$ with $0<a<b<c^{2} \alpha / 2$, 
where $\frac{1}{c}$ is the 2-uniformly convexity constant of $E$. If $\sum_{i=0}^{\infty} \alpha_{n, i}=1$ for all $n \geq 0, \lim \inf _{n}$ $\rightarrow \infty\left(1-\beta_{n}\right)>0$ and $\lim _{\inf _{n \rightarrow \infty}} \alpha_{n, 0} \alpha_{n, i}>0$ for all $i \geq 1$, then $\left\{x_{n}\right\}$ converges strongly to $p \in F$, where $p=\Pi_{F} x_{0}$.

Proof. We first show that $C_{n+1}$ is closed and convex for each $n \geq 0$. Clearly, $C_{1}=C$ is closed and convex. Suppose that $C_{n}$ is closed and convex for each $n \in \mathbb{N}$. Since for any $z \in C_{n}$, we know $\varphi\left(z, u_{n}\right) \leq \varphi\left(z, x_{n}\right)+\theta n$ is equivalent to $2\left\langle z, J x_{n}-J u_{n}\right\rangle \leq\left\|x_{n}\right\|^{2}-\|$ $u_{n}\|\|^{2}+\theta_{n}$. So, $C_{n+1}$ is closed and convex.

Next, we show that $F \subset C_{n}$ for all $n \geq 0$. Since $u_{n}=\Omega_{n}^{m} y_{n}$, when $\Omega_{n}^{j}=T_{r_{j, n}}^{Q_{j}} T_{r_{j-1, n}}^{Q_{j-1}} \cdots T_{r_{2, n}}^{Q_{2}} T_{r_{1, n}}^{Q_{1}}, j=1,2,3, \ldots, m, \Omega_{n}^{0}=I$, by the convexity of $\|\cdot\|^{2}$, property of $\varphi$, Lemma 2.9 and by uniformly quasi- $\varphi$-asymptotically nonexpansive of $S_{n}$ for each $q$ $\in F \subset C_{n}$, we have

$$
\begin{aligned}
\phi\left(q, u_{n}\right) & =\phi\left(q, \Omega_{n}^{m} y_{n}\right) \\
& \leq \phi\left(q, y_{n}\right) \\
& =\phi\left(q, J^{-1}\left(\beta_{n} J x_{n}+\left(1-\beta_{n}\right) J z_{n}\right)\right. \\
& =\|q\|^{2}-2\left\langle q, \beta_{n} J x_{n}+\left(1-\beta_{n}\right) J z_{n}\right\rangle+\left\|\beta_{n} J x_{n}+\left(1-\beta_{n}\right) J z_{n}\right\|^{2} \\
& \leq\|q\|^{2}-2 \beta_{n}\left\langle q, J x_{n}\right\rangle-2\left(1-\beta_{n}\right)\left\langle q, J z_{n}\right\rangle+\beta_{n}\left\|x_{n}\right\|^{2}+\left(1-\beta_{n}\right)\left\|z_{n}\right\|^{2} \\
& =\beta_{n} \phi\left(q, x_{n}\right)+\left(1-\beta_{n}\right) \phi\left(q, z_{n}\right)
\end{aligned}
$$

and

$$
\begin{aligned}
\phi\left(q, z_{n}\right)= & \phi\left(q, J^{-1}\left(\alpha_{n, 0} 0 x_{n}+\sum_{i=1}^{\infty} \alpha_{n, j} S_{i}^{n} v_{n}\right)\right) \\
= & \|q\|^{2}-2\left\langle q, \alpha_{n, 0} J x_{n}+\sum_{i=1}^{\infty} \alpha_{n, i} J S_{i}^{n} v_{n}\right\rangle+\left\|\alpha_{n, 0} J x_{n}+\sum_{i=1}^{\infty} \alpha_{n, i} J S_{i}^{n} v_{n}\right\|^{2} \\
= & \|q\|^{2}-2 \alpha_{n, 0}\left\langle q, J x_{n}\right\rangle-2 \sum_{i=1}^{\infty} \alpha_{n, i}\left\langle q, J S_{i}^{n} v_{n}\right\rangle+\left\|\alpha_{n, 0} J x_{n}+\sum_{i=1}^{\infty} \alpha_{n, i} J S_{i}^{n} v_{n}\right\|^{2} \\
\leq & \|q\|^{2}-2 \alpha_{n, 0}\left\langle q, J x_{n}\right\rangle-2 \sum_{i=1}^{\infty} \alpha_{n, i}\left\langle q, J S_{i}^{v_{n}} v_{n}\right\rangle+\alpha_{n, 0}\left\|J x_{n}\right\|^{2}+\sum_{i=1}^{\infty} \alpha_{n, i}\left\|J S_{i}^{n} v_{n}\right\|^{2} \\
& -\alpha_{n, 0} \alpha_{n, j} g\left\|J v_{n}-J S_{j}^{n} v_{n}\right\| \\
= & \|q\|^{2}-2 \alpha_{n, 0}\left\langle q, J x_{n}\right\rangle+\alpha_{n, 0}\left\|J x_{n}\right\|^{2}-2 \sum_{i=1}^{\infty} \alpha_{n, i}\left\langle q, J S_{i}^{n} v_{n}\right\rangle \\
& +\sum_{i=1}^{\infty} \alpha_{n, i}\left\|J S_{i}^{n} v_{n}\right\|^{2}-\alpha_{n, 0} \alpha_{n, j} g\left\|J v_{n}-J S_{j}^{n} v_{n}\right\| \\
= & \alpha_{n, 0} \phi\left(q, x_{n}\right)+\sum_{i=1}^{\infty} \alpha_{n, i} \phi\left(q, S_{i}^{n} v_{n}\right)-\alpha_{n, 0} \alpha_{n, j} g\left\|J v_{n}-J S_{j}^{n} v_{n}\right\| \\
\leq & \alpha_{n, 0} \phi\left(q, x_{n}\right)+\sum_{i=1}^{\infty} \alpha_{n, i} k_{n} \phi\left(q, v_{n}\right)-\alpha_{n, 0} \alpha_{n, j} g\left\|J v_{n}-J S_{j}^{n} v_{n}\right\| .
\end{aligned}
$$

It follows from Lemma 2.7 that

$$
\begin{aligned}
\phi\left(q, v_{n}\right) & =\phi\left(q, \Pi_{C} J^{-1}\left(J x_{n}-\lambda_{n} A x_{n}\right)\right) \\
& \leq \phi\left(q, J^{-1}\left(J x_{n}-\lambda_{n} A x_{n}\right)\right) \\
& =V\left(q, J x_{n}-\lambda_{n} A x_{n}\right) \\
& \leq V\left(q,\left(J x_{n}-\lambda_{n} A x_{n}\right)+\lambda_{n} A x_{n}\right)-2\left\langle J^{-1}\left(J x_{n}-\lambda_{n} A x_{n}\right)-q, \lambda_{n} A x_{n}\right\rangle \\
& =V\left(q, J x_{n}\right)-2 \lambda_{n}\left\langle J^{-1}\left(J x_{n}-\lambda_{n} A x_{n}\right)-q, A x_{n}\right\rangle \\
& =\phi\left(q, x_{n}\right)-2 \lambda_{n}\left\langle x_{n}-q, A x_{n}\right\rangle+2\left\langle J^{-1}\left(J x_{n}-\lambda_{n} A x_{n}\right)-x_{n},-\lambda_{n} A x_{n}\right\rangle .
\end{aligned}
$$

Since $q \in \operatorname{VI}(A, C)$ and $A$ is an $\alpha$-inverse-strongly monotone mapping, we have

$$
\begin{aligned}
-2 \lambda_{n}\left\langle x_{n}-q, A x_{n}\right\rangle & =-2 \lambda_{n}\left\langle x_{n}-q, A x_{n}-A q\right\rangle-2 \lambda_{n}\left\langle x_{n}-q, A q\right\rangle \\
& \leq-2 \lambda_{n}\left\langle x_{n}-q, A x_{n}-A q\right\rangle \\
& \leq-2 \alpha \lambda_{n}\left\|A x_{n}-A q\right\|^{2} .
\end{aligned}
$$

From Lemma 2.2 and $\left\|A x_{n}\right\| \leq\left\|A x_{n}-A q\right\|, \forall q \in \operatorname{VI}(A, C)$, we also have

$$
\begin{aligned}
2\left\langle J^{-1}\left(J x_{n}-\lambda_{n} A x_{n}\right)-x_{n},-\lambda_{n} A x_{n}\right\rangle & =2\left\langle J^{-1}\left(J x_{n}-\lambda_{n} A x_{n}\right)-J^{-1}\left(J x_{n}\right),-\lambda_{n} A x_{n}\right\rangle \\
& \leq 2\left\|J^{-1}\left(J x_{n}-\lambda_{n} A x_{n}\right)-J^{-1}\left(J x_{n}\right)\right\|\left\|\lambda_{n} A x_{n}\right\| \\
& \leq \frac{4}{c^{2}}\left\|J J^{-1}\left(J x_{n}-\lambda_{n} A x_{n}\right)-J J^{-1}\left(J x_{n}\right)\right\|\left\|\lambda_{n} A x_{n}\right\| \\
& =\frac{4}{c^{2}}\left\|J x_{n}-\lambda_{n} A x_{n}-J x_{n}\right\|\left\|\lambda_{n} A x_{n}\right\| \\
& =\frac{4}{c^{2}}\left\|\lambda_{n} A x_{n}\right\|^{2} \\
& =\frac{4}{c^{2}} \lambda_{n}^{2}\left\|A x_{n}\right\|^{2} \\
& \leq \frac{4}{c^{2}} \lambda_{n}^{2}\left\|A x_{n}-A q\right\|^{2} .
\end{aligned}
$$


Substituting (3.5) and (3.6) into (3.4), we obtain

$$
\begin{aligned}
\phi\left(q, v_{n}\right) & \leq \phi\left(q, x_{n}\right)-2 \alpha \lambda_{n}\left\|A x_{n}-A q\right\|^{2}+\frac{4}{c^{2}} \lambda_{n}^{2}\left\|A x_{n}-A q\right\|^{2} \\
& =\phi\left(q, x_{n}\right)+2 \lambda_{n}\left(\frac{2}{c^{2}} \lambda_{n}-\alpha\right)\left\|A x_{n}-A q\right\|^{2} \\
& \leq \phi\left(q, x_{n}\right) .
\end{aligned}
$$

Substituting (3.7) into (3.3), we also have

$$
\begin{aligned}
\phi\left(q, z_{n}\right) & \leq \alpha_{n, 0} \phi\left(q, x_{n}\right)+\sum_{i=1}^{\infty} \alpha_{n, i} k_{n} \phi\left(q, x_{n}\right)-\alpha_{n, 0} \alpha_{n, j} g\left\|J v_{n}-J S_{j}^{n} v_{n}\right\| \\
& \leq \alpha_{n, 0} k_{n} \phi\left(q, x_{n}\right)+\sum_{i=1}^{\infty} \alpha_{n, i} k_{n} \phi\left(q, x_{n}\right)-\alpha_{n, 0} \alpha_{n, j} g\left\|J v_{n}-J S_{j}^{n} v_{n}\right\| \\
& =k_{n} \phi\left(q, x_{n}\right)-\alpha_{n, 0} \alpha_{n, j} g\left\|J v_{n}-J S_{j}^{n} v_{n}\right\| \\
& \leq \phi\left(q, x_{n}\right)+\sup _{q \in F}\left(k_{n}-1\right) \phi\left(q, x_{n}\right)-\alpha_{n, 0} \alpha_{n, j} g\left\|J v_{n}-J S_{j}^{n} v_{n}\right\| \\
& =\phi\left(q, x_{n}\right)+\theta_{n}-\alpha_{n, 0} \alpha_{n, j} g\left\|J v_{n}-J S_{j}^{n} v_{n}\right\| \\
& \leq \phi\left(q, x_{n}\right)+\theta_{n} .
\end{aligned}
$$

and substituting (3.8) into (3.2), we also have

$$
\phi\left(q, u_{n}\right) \leq \phi\left(q, x_{n}\right)+\theta_{n} .
$$

This shows that $q \in C_{n+1}$ implies that $F \subset C_{n+1}$ and hence, $F \subset C_{n}$ for all $n \geq 0$. This implies that the sequence $\left\{x_{n}\right\}$ is well defined. From definition of $C_{n+1}$ that $x_{n}=\Pi_{C_{n}} x_{0}$ and $x_{n+1}=\Pi_{C_{n+1}} x_{0}, \in C_{n+1} \subset C_{n}$, we have

$$
\phi\left(x_{n}, x_{0}\right) \leq \phi\left(x_{n+1}, x_{0}\right), \quad \forall n \geq 0 .
$$

By Lemma 2.6, we get

$$
\begin{aligned}
\phi\left(x_{n}, x_{0}\right) & =\phi\left(\Pi_{C_{n}} x_{0}, x_{0}\right) \\
& \leq \phi\left(q, x_{0}\right)-\phi\left(q, x_{n}\right) \\
& \leq \phi\left(q, x_{0}\right), \quad \forall q \in F .
\end{aligned}
$$

From (3.10) and (3.11), then $\left\{\varphi\left(x_{n}, x_{0}\right)\right\}$ are nondecreasing and bounded. So, we obtain that $\lim _{n \rightarrow \infty} \phi\left(x_{n}, x_{0}\right)$ exists. In particular, by (1.9), the sequence $\left\{\left(|| x_{n}\|-\| x_{0} \|\right)^{2}\right.$ is bounded. This implies $\left\{x_{n}\right\}$ is also bounded. Denote

$$
M=\sup _{n \geq 0}\left\{\left\|x_{n}\right\|\right\}<\infty .
$$

Moreover, by the definition of $\theta_{n}$ and (3.12), it follows that

$$
\theta_{n} \rightarrow 0 \quad \text { as } n \rightarrow \infty
$$

Next, we show that $\left\{x_{n}\right\}$ is a Cauchy sequence in $C$. Since $x_{m}=\Pi_{C_{m}} x_{0} \in C_{m} \subset C_{n}$, for $m>n$, by Lemma 2.6, we have

$$
\begin{aligned}
\phi\left(x_{m}, x_{n}\right) & =\phi\left(x_{m}, \Pi_{C_{n}} x_{0}\right) \\
& \leq \phi\left(x_{m}, x_{0}\right)-\phi\left(\Pi_{C_{n}} x_{0}, x_{0}\right) \\
& =\phi\left(x_{m}, x_{0}\right)-\phi\left(x_{n}, x_{0}\right) .
\end{aligned}
$$

Since $\lim _{n \rightarrow \infty} \varphi\left(x_{n}, x_{0}\right)$ exists and we take $m, n \rightarrow \infty$, we get $\varphi\left(x_{m}, x_{n}\right) \rightarrow 0$. From Lemma 2.4, we have $\lim _{n \rightarrow \infty}|| x_{m}-x_{n} \|=0$. Thus, $\left\{x_{n}\right\}$ is a Cauchy sequence, and by the completeness of $E$, there exists a point $p \in C$ such that $x_{n} \rightarrow p$ as $n \rightarrow \infty$.

Now, we claim that $\left\|J u_{n}-J x_{n}\right\| \rightarrow 0$, as $n \rightarrow \infty$. By definition of $x_{n}=\Pi_{C_{n}} x_{0}$, we have

$$
\begin{aligned}
\phi\left(x_{n+1}, x_{n}\right) & =\phi\left(x_{n+1}, \Pi_{C_{n}} x_{0}\right) \\
& \leq \phi\left(x_{n+1}, x_{0}\right)-\phi\left(\Pi_{C_{n}} x_{0}, x_{0}\right) \\
& =\phi\left(x_{n+1}, x_{0}\right)-\phi\left(x_{n}, x_{0}\right) .
\end{aligned}
$$


Since $\lim _{n \rightarrow \infty} \varphi\left(x_{n}, x_{0}\right)$ exists, we also have

$$
\lim _{n \rightarrow \infty} \phi\left(x_{n+1}, x_{n}\right)=0 \text {. }
$$

Again from Lemma 2.4 that

$$
\lim _{n \rightarrow \infty}\left\|x_{n+1}-x_{n}\right\|=0
$$

Since $J$ is uniformly norm-to-norm continuous on bounded subsets of $E$, we obtain

$$
\lim _{n \rightarrow \infty}\left\|J x_{n+1}-J x_{n}\right\|=0 .
$$

Since $x_{n+1}=\Pi_{C_{n+1}} x_{0} \in C_{n+1} \subset C_{n}$ and the definition of $C_{n+1}$, we have

$$
\phi\left(x_{n+1}, u_{n}\right) \leq \phi\left(x_{n+1}, x_{n}\right)+\theta_{n} .
$$

By (3.13) and (3.14) that

$$
\lim _{n \rightarrow \infty} \phi\left(x_{n+1}, u_{n}\right)=0 .
$$

Again applying Lemma 2.4, we have

$$
\lim _{n \rightarrow \infty}\left\|x_{n+1}-u_{n}\right\|=0 .
$$

Since

$$
\begin{aligned}
\left\|u_{n}-x_{n}\right\| & =\left\|u_{n}-x_{n+1}+x_{n+1}-x_{n}\right\| \\
& \leq\left\|u_{n}-x_{n+1}\right\|+\left\|x_{n+1}-x_{n}\right\| .
\end{aligned}
$$

It follows from (3.15) and (3.18) that

$$
\lim _{n \rightarrow \infty}\left\|u_{n}-x_{n}\right\|=0
$$

Since $J$ is uniformly norm-to-norm continuous on bounded subsets of $E$, we also have

$$
\lim _{n \rightarrow \infty}\left\|J u_{n}-J x_{n}\right\|=0 .
$$

Next, we will show that $p \in F:=\cap_{j=1}^{m} \operatorname{GMEP}\left(f_{j}, B_{j}, \varphi_{j}\right) \cap\left(\cap_{i=1}^{\infty} F\left(S_{i}\right)\right) \cap \operatorname{VI}(A, C)$.

(a) We show that $p \in \cap_{i=1}^{\infty} F\left(S_{i}\right)$. Since $x_{n+1}=\Pi_{C_{n+1}} x_{0} \in C_{n+1} \subset C_{n}$, it follow from (3.8), we have

$$
\phi\left(x_{n+1}, z_{n}\right) \leq \phi\left(x_{n+1}, x_{n}\right)+\theta_{n}
$$

by (3.13) and (3.14), we get

$$
\lim _{n \rightarrow \infty} \phi\left(x_{n+1}, z_{n}\right)=0
$$

again from Lemma 2.4 that

$$
\lim _{n \rightarrow \infty}\left\|x_{n+1}-z_{n}\right\|=0 .
$$

Since $J$ is uniformly norm-to-norm continuous, we obtain

$$
\lim _{n \rightarrow \infty}\left\|J x_{n+1}-J z_{n}\right\|=0 .
$$


From (3.50), we note that

$$
\begin{aligned}
\left\|J x_{n+1}-J z_{n}\right\| & =\left\|J x_{n+1}-\left(\alpha_{n, 0} J x_{n}+\sum_{i=1}^{\infty} \alpha_{n, i} J S_{i}^{n} v_{n}\right)\right\| \\
& =\left\|\alpha_{n, 0} J x_{n+1}-\alpha_{n, 0} J x_{n}+\sum_{i=1}^{\infty} \alpha_{n, i} J x_{n+1}-\sum_{i=1}^{\infty} \alpha_{n, i} J S_{i}^{n} v_{n}\right\| \\
& =\left\|\alpha_{n, 0}\left(J x_{n+1}-J x_{n}\right)+\sum_{i=1}^{\infty} \alpha_{n, i}\left(J x_{n+1}-J S_{i}^{n} v_{n}\right)\right\| \\
& =\left\|\sum_{i=1}^{\infty} \alpha_{n, i}\left(J x_{n+1}-J S_{i}^{n} v_{n}\right)-\alpha_{n, 0}\left(J x_{n}-J x_{n+1}\right)\right\| \\
& \geq \sum_{i=1}^{\infty} \alpha_{n, i}\left\|J x_{n+1}-J S_{i}^{n} v_{n}\right\|-\alpha_{n, 0}\left\|J x_{n}-J x_{n+1}\right\|,
\end{aligned}
$$

and hence

$$
\left\|J x_{n+1}-J S_{i}^{n} v_{n}\right\| \leq \frac{1}{\sum_{i=1}^{\infty} \alpha_{n, i}}\left(\left\|J x_{n+1}-J z_{n}\right\|+\alpha_{n, 0}\left\|J x_{n}-J x_{n+1}\right\|\right) .
$$

From (3.16), (3.23) and $\lim \inf _{n \rightarrow \infty} \sum_{i=1}^{\infty} \alpha_{n, i}>0$, we obtain that

$$
\lim _{n \rightarrow \infty}\left\|J x_{n+1}-J S_{i}^{n} v_{n}\right\|=0 .
$$

Since $J^{1}$ is uniformly norm-to-norm continuous on bounded sets, we have

$$
\lim _{n \rightarrow \infty}\left\|x_{n+1}-S_{i}^{n} v_{n}\right\|=0 .
$$

Using the triangle inequality that

$$
\begin{aligned}
\left\|x_{n}-S_{i}^{n} v_{n}\right\| & =\left\|x_{n}-x_{n+1}+x_{n+1}-S_{i}^{n} v_{n}\right\| \\
& \leq\left\|x_{n}-x_{n+1}\right\|+\left\|x_{n+1}-S_{i}^{n} v_{n}\right\| .
\end{aligned}
$$

From (3.15) and (3.26), we have

$$
\lim _{n \rightarrow \infty}\left\|x_{n}-S_{i}^{n} v_{n}\right\|=0 .
$$

On the other hand, we note that

$$
\begin{aligned}
\phi\left(q, x_{n}\right)-\phi\left(q, u_{n}\right)+\theta_{n} & =\left\|x_{n}\right\|^{2}-\left\|u_{n}\right\|^{2}-2\left\langle q, J x_{n}-J u_{n}\right\rangle+\theta_{n} \\
& \leq\left\|x_{n}-u_{n}\right\|\left(\left\|x_{n}\right\|+\left\|u_{n}\right\|\right)+2\|q\|\left\|J x_{n}-J u_{n}\right\|+\theta_{n} .
\end{aligned}
$$

It follows from $\theta_{n} \rightarrow 0,\left\|x_{n}-u_{n}\right\| \rightarrow 0$ and $\left\|J x_{n}-J u_{n}\right\| \rightarrow 0$, that

$$
\phi\left(q, x_{n}\right)-\phi\left(q, u_{n}\right)+\theta_{n} \rightarrow 0 \quad \text { as } n \rightarrow \infty .
$$

From (3.2), (3.3) and (3.7) that

$$
\begin{aligned}
\phi\left(q, u_{n}\right) \leq & \phi\left(q, y_{n}\right) \\
\leq & \beta_{n} \phi\left(q, x_{n}\right)+\left(1-\beta_{n}\right) \phi\left(q, z_{n}\right) \\
\leq & \beta_{n} \phi\left(q, x_{n}\right)+\left(1-\beta_{n}\right)\left[\alpha_{n, 0} \phi\left(q, x_{n}\right)+\sum_{i=1}^{\infty} \alpha_{n, i} k_{n} \phi\left(q, v_{n}\right)\right. \\
& \left.-\alpha_{n, 0} \alpha_{n, j} g\left\|J v_{n}-J S_{j}^{n} v_{n}\right\|\right] \\
= & \beta_{n} \phi\left(q, x_{n}\right)+\left(1-\beta_{n}\right) \alpha_{n, 0} \phi\left(q, x_{n}\right)+\left(1-\beta_{n}\right) \sum_{i=1}^{\infty} \alpha_{n, i} k_{n} \phi\left(q, v_{n}\right) \\
& -\left(1-\beta_{n}\right) \alpha_{n, 0} \alpha_{n, j} g\left\|J v_{n}-J S_{j}^{n} v_{n}\right\| \\
\leq & \beta_{n} \phi\left(q, x_{n}\right)+\left(1-\beta_{n}\right) \alpha_{n, 0} \phi\left(q, x_{n}\right)+\left(1-\beta_{n}\right) \sum_{i=1}^{\infty} \alpha_{n, i} k_{n} \phi\left(q, v_{n}\right) \\
\leq & \beta_{n} \phi\left(q, x_{n}\right)+\left(1-\beta_{n}\right) \alpha_{n, 0} \phi\left(q, x_{n}\right)+\left(1-\beta_{n}\right) \sum_{i=1}^{\infty} \alpha_{n, i} k_{n}\left[\phi\left(q, x_{n}\right)-2 \lambda_{n}\left(\alpha-\frac{2}{c^{2}} \lambda_{n}\right)\left\|A x_{n}-A q\right\|^{2}\right] \\
\leq & \beta_{n} \phi\left(q, x_{n}\right)+\left(1-\beta_{n}\right) \alpha_{n, 0} k_{n} \phi\left(q, x_{n}\right)+\left(1-\beta_{n}\right) \sum_{i=1}^{\infty} \alpha_{n, i} k_{n} \phi\left(q, x_{n}\right) \\
& -\left(1-\beta_{n}\right) \sum_{i=1}^{\infty} \alpha_{n, i} k_{n} 2 \lambda_{n}\left(\alpha-\frac{2}{c^{2}} \lambda_{n}\right)\left\|A x_{n}-A q\right\|^{2} \\
\leq & \beta_{n} k_{n} \phi\left(q, x_{n}\right)+\left(1-\beta_{n}\right) k_{n} \phi\left(q, x_{n}\right)-\left(1-\beta_{n}\right) \sum_{i=1}^{\infty} \alpha_{n, i} k_{n} 2 \lambda_{n}\left(\alpha-\frac{2}{c^{2}} \lambda_{n}\right)\left\|A x_{n}-A q\right\|^{2} \\
= & \left.k_{n} \phi\left(q, x_{n}\right)-\left(1-\beta_{n}\right) \sum_{i=1}^{\infty} \alpha_{n, i} k_{n} 2 \lambda_{n}\left(\alpha-\frac{2}{c^{2}} \lambda_{n}\right)\left\|A x_{n}-A q\right\|^{2}\right] \\
\leq & \phi\left(q, x_{n}\right)+\sup _{q \in F}\left(k_{n}-1\right) \phi\left(q, x_{n}\right)-\left(1-\beta_{n}\right) \sum_{i=1}^{\infty} \alpha_{n, i} k_{n} 2 \lambda_{n}\left(\alpha-\frac{2}{c^{2}} \lambda_{n}\right)\left\|A x_{n}-A q\right\|^{2} \\
= & \phi\left(q, x_{n}\right)+\theta_{n}-\left(1-\beta_{n}\right) \sum_{i=1}^{\infty} \alpha_{n, i} k_{n} 2 \lambda_{n}\left(\alpha-\frac{2}{c^{2}} \lambda_{n}\right)\left\|A x_{n}-A q\right\|^{2},
\end{aligned}
$$


and hence

$$
\begin{aligned}
2 a\left(\alpha-\frac{2 b}{c^{2}}\right)\left\|A x_{n}-A q\right\|^{2} & \leq 2 \lambda_{n}\left(\alpha-\frac{2}{c^{2}} \lambda_{n}\right)\left\|A x_{n}-A q\right\|^{2} \\
& \leq \frac{1}{\left(1-\beta_{n}\right) \sum_{i=1}^{\infty} \alpha_{n, i} k_{n}}\left(\phi\left(q, x_{n}\right)-\phi\left(q, u_{n}\right)+\theta_{n}\right) .
\end{aligned}
$$

From (3.28), $\left\{\lambda_{n}\right\} \subset[a, b]$ for some $a, b$ with $0<a<b<c^{2} \alpha / 2, \lim _{\inf _{n \rightarrow \infty}}\left(1-\beta_{n}\right)$ $>0$ and $\lim \inf _{n \rightarrow \infty} \alpha_{n, 0} \alpha_{n, i}>0$, for $i \geq 0$ and $k_{n} \rightarrow 1$ as $n \rightarrow \infty$, we obtain that

$$
\lim _{n \rightarrow \infty}\left\|A x_{n}-A q\right\|=0 .
$$

From Lemmas 2.6, 2.7 and (3.6), we compute

$$
\begin{aligned}
\phi\left(x_{n}, v_{n}\right) & =\phi\left(x_{n}, \Pi_{C} J^{-1}\left(J x_{n}-\lambda_{n} A x_{n}\right)\right) \\
& \leq \phi\left(x_{n}, J^{-1}\left(J x_{n}-\lambda_{n} A x_{n}\right)\right) \\
& =V\left(x_{n}, J x_{n}-\lambda_{n} A x_{n}\right) \\
& \leq V\left(x_{n},\left(J x_{n}-\lambda_{n} A x_{n}\right)+\lambda_{n} A x_{n}\right)-2\left\langle J^{-1}\left(J x_{n}-\lambda_{n} A x_{n}\right)-x_{n}, \lambda_{n} A x_{n}\right\rangle \\
& =\phi\left(x_{n}, x_{n}\right)+2\left\langle J^{-1}\left(J x_{n}-\lambda_{n} A x_{n}\right)-x_{n},-\lambda_{n} A x_{n}\right\rangle \\
& =2\left\langle J^{-1}\left(J x_{n}-\lambda_{n} A x_{n}\right)-x_{n},-\lambda_{n} A x_{n}\right\rangle \\
& \leq \frac{4 \lambda_{n}^{2}}{c^{2}}\left\|A x_{n}-A q\right\|^{2} \\
& \leq \frac{4 b^{2}}{c^{2}}\left\|A x_{n}-A q\right\|^{2} .
\end{aligned}
$$

Applying Lemma 2.4 and (3.30) that

$$
\lim _{n \rightarrow \infty}\left\|x_{n}-v_{n}\right\|=0
$$

and we also obtain

$$
\lim _{n \rightarrow \infty}\left\|J x_{n}-J v_{n}\right\|=0 .
$$

Since $S_{i}^{n}$ is continuous, for any $i \geq 1$

$$
\lim _{n \rightarrow \infty}\left\|S_{i}^{n} x_{n}-S_{i}^{n} v_{n}\right\|=0 .
$$

Again by the triangle inequality, we get

$$
\left\|x_{n}-S_{i}^{n} x_{n}\right\| \leq\left\|x_{n}-S_{i}^{n} v_{n}\right\|+\left\|S_{i}^{n} v_{n}-S_{i}^{n} x_{n}\right\| .
$$

From (3.27) and (3.33), we have

$$
\lim _{n \rightarrow \infty}\left\|x_{n}-S_{i}^{n} x_{n}\right\|=0, \quad \forall i \geq 1 .
$$

By using triangle inequality, we get

$$
\left\|S_{i}^{n} x_{n}-p\right\| \leq\left\|S_{i}^{n} x_{n}-x_{n}\right\|+\left\|x_{n}-p\right\|, \quad \forall i \geq 1 .
$$

We know that $x_{n} \rightarrow p$ as $n \rightarrow \infty$ and from (3.34)

$$
S_{i}^{n} x_{n} \rightarrow p \quad \text { for each } i \geq 1 .
$$

Moreover, by the assumption that $\forall i \geq 1, S_{i}$ is uniformly $L_{i}$-Lipschitz continuous, and hence we have.

$$
\begin{aligned}
\left\|S_{i}^{n+1} x_{n}-S_{i}^{n} x_{n}\right\| & \leq\left\|S_{i}^{n+1} x_{n}-S_{i}^{n+1} x_{n+1}\right\|+\left\|S_{i}^{n+1} x_{n+1}-x_{n+1}\right\|+\left\|x_{n+1}-x_{n}\right\|+\left\|x_{n}-S_{i}^{n} x_{n}\right\| \\
& \leq\left(L_{i}+1\right)\left\|x_{n+1}-x_{n}\right\|+\left\|S_{i}^{n+1} x_{n+1}-x_{n+1}\right\|+\left\|x_{n}-S_{i}^{n} x_{n}\right\| .
\end{aligned}
$$

By (3.15) and (3.34), it yields that $\left\|S_{i}^{n+1} x_{n}-S_{i}^{n} x_{n}\right\| \rightarrow 0$. From $S_{i}^{n} x_{n} \rightarrow p$, we have $S_{i}^{n+1} x_{n} \rightarrow p$, that is $S_{i} S_{i}^{n} x_{n} \rightarrow p$. In view of closeness of $S_{i}$, we have $S_{i} p=p$, for all $i \geq 1$. This implies that $p \in \cap_{i=1}^{\infty} F\left(S_{i}\right)$. 
(b) We show that $p \in \cap_{j=1}^{m} \operatorname{GMEP}\left(f_{j}, B_{j}, \varphi_{j}\right)$.

Let $u_{n}=\Omega_{n}^{m} y_{n}$, when $\Omega_{n}^{j}=T_{r_{j, n}}^{Q_{j}} T_{r_{j-1, n}}^{Q_{j-1}} \cdots T_{r_{2, n}}^{Q_{2}} T_{r_{1, n}}^{Q_{1}} j=1,2,3, \ldots, m$ and $\Omega_{n}^{0}=I$, we obtain

$$
\begin{aligned}
\phi\left(q, u_{n}\right)= & \phi\left(q, \Omega_{n}^{m} y_{n}\right) \\
\leq & \phi\left(q, \Omega_{n}^{m-1} y_{n}\right) \\
\leq & \phi\left(q, \Omega_{n}^{m-2} y_{n}\right) \\
& \vdots \\
\leq & \phi\left(q, \Omega_{n}^{j} y_{n}\right) .
\end{aligned}
$$

By Lemma (2.11)(5), we have for $j=1,2,3, \ldots, m$

$$
\begin{aligned}
\phi\left(\Omega_{n}^{j} y_{n}, y_{n}\right)+\theta_{n} & \leq \phi\left(q, y_{n}\right)-\phi\left(q, \Omega_{n}^{j} y_{n}\right)+\theta_{n} \\
& \leq \phi\left(q, x_{n}\right)-\phi\left(q, \Omega_{n}^{j} y_{n}\right)+\theta_{n} \\
& \leq \phi\left(q, x_{n}\right)-\phi\left(q, u_{n}\right)+\theta_{n} .
\end{aligned}
$$

From (3.13) and (3.28), we get $\phi\left(\Omega_{n}^{j} y_{n}, y_{n}\right) \rightarrow 0$ as $n \rightarrow \infty$, for $j=1,2,3, \ldots, m$ and Lemma 2.4 implies that

$$
\lim _{n \rightarrow \infty}\left\|\Omega_{n}^{j} y_{n}-y_{n}\right\|=0, \forall j=1,2,3, \ldots, m .
$$

Since $x_{n+1}=\Pi_{C_{n+1}} x_{0} \in C_{n+1} \subset C_{n}$, it follows from (3.2) and (3.8) that

$$
\phi\left(x_{n+1}, y_{n}\right) \leq \phi\left(x_{n+1}, x_{n}\right)+\theta_{n} .
$$

By (3.13) and (3.14), we have

$$
\lim _{n \rightarrow \infty} \phi\left(x_{n+1}, y_{n}\right)=0 \text {. }
$$

Applying Lemma 2.4 that

$$
\lim _{n \rightarrow \infty}\left\|x_{n+1}-y_{n}\right\|=0 .
$$

Using the triangle inequality, we obtain

$$
\left\|x_{n}-y_{n}\right\| \leq\left\|x_{n}-x_{n+1}\right\|+\left\|x_{n+1}-y_{n}\right\| .
$$

From (3.15) and (3.39), we get

$$
\lim _{n \rightarrow \infty}\left\|x_{n}-y_{n}\right\|=0 .
$$

Since $x_{n} \rightarrow p$ and $\left\|x_{n}-y_{n}\right\| \rightarrow 0$, we have $y_{n} \rightarrow p$ as $n \rightarrow \infty$.

Again by using the triangle inequality, we have for $j=1,2,3, \ldots, m$

$$
\left\|p-\Omega_{n}^{j} y_{n}\right\| \leq\left\|p-y_{n}\right\|+\left\|y_{n}-\Omega_{n}^{j} y_{n}\right\| .
$$

From (3.38) and $y_{n} \rightarrow p$ as $n \rightarrow \infty$, we get

$$
\lim _{n \rightarrow \infty}\left\|p-\Omega_{n}^{j} y_{n}\right\|=0, \forall j=1,2,3, \ldots, m .
$$

By using the triangle inequality, we obtain

$$
\left\|\Omega_{n}^{j} y_{n}-\Omega_{n}^{j-1} y_{n}\right\| \leq\left\|\Omega_{n}^{j} y_{n}-p\right\|+\left\|p-\Omega_{n}^{j-1} y_{n}\right\| .
$$

From (3.41), we have

$$
\lim _{n \rightarrow \infty}\left\|\Omega_{n}^{j} y_{n}-\Omega_{n}^{j-1} y_{n}\right\|=0, \forall j=1,2,3, \ldots, m .
$$


Since $\left\{r_{j, n}\right\} \subset[d, \infty)$ and $J$ is uniformly continuous on any bounded subset of $E$,

$$
\lim _{n \rightarrow \infty} \frac{\left\|J \Omega_{n}^{j} y_{n}-J \Omega_{n}^{j-1} y_{n}\right\|}{r_{j, n}}=0, \forall j=1,2,3, \ldots, m
$$

From Lemma 2.11, we get for $j=1,2,3, \ldots, m$

$$
Q_{j}\left(\Omega_{n}^{j} y_{n}, y\right)+\frac{1}{r_{j, n}}\left\langle y-\Omega_{n}^{j} y_{n}, J \Omega_{n}^{j} y_{n}-J \Omega_{n}^{j-1} y_{n}\right\rangle \geq 0, \quad \forall y \in C .
$$

From (A2),

$$
\frac{1}{r_{j, n}}\left\langle y-\Omega_{n}^{j} y_{n}, J \Omega_{n}^{j} y_{n}-J \Omega_{n}^{j-1} y_{n}\right\rangle \geq Q_{j}\left(y, \Omega_{n}^{j} y_{n}\right), \quad \forall y \in C, \forall j=1,2,3, \ldots, m .
$$

From (3.41) and (3.43), we have

$$
0 \geq Q_{j}(y, p), \quad \forall y \in C, \forall j=1,2,3, \ldots, m .
$$

For $t$ with $0<t \leq 1$ and $y \in C$; let $y_{t}=t y+(1-t) p$. Then, we get that $y_{t} \in C$. From (3.44), and it follows that

$$
Q_{j}\left(y_{t}, p\right) \leq 0, \quad \forall y \in C, \forall j=1,2,3, \ldots, m .
$$

By the conditions (A1) and (A4), we have for $j=1,2,3, \ldots, m$

$$
\begin{aligned}
0 & =Q_{j}\left(y_{t}, y_{t}\right) \\
& \leq t Q_{j}\left(y_{t}, y\right)+(1-t) Q_{j}\left(y_{t}, p\right) \\
& \leq t Q_{j}\left(y_{t}, y\right) \\
& =Q_{j}\left(y_{t}, y\right) .
\end{aligned}
$$

From (A3) and letting $t \rightarrow 0$, This implies that $p \in \operatorname{GMEP}\left(f_{j}, B_{j}, \phi_{j}\right), \forall j=1,2,3, \ldots$, $m$. Therefore $p \in \cap_{j=1}^{m} \operatorname{GMEP}\left(f_{j}, B_{j}, \varphi_{j}\right)$

(c) We show that $p \in \operatorname{VI}(A, C)$. Indeed, define $U \subset E \times E^{*}$ by

$$
U v= \begin{cases}A v+N_{C}(v), & v \in C \\ \emptyset, & v \notin C\end{cases}
$$

By Lemma 2.8, $U$ is maximal monotone and $U^{-1} 0=\mathrm{VI}(A, C)$. Let $(v, w) \in G(U)$. Since $w \in U v=A v+N_{C}(v)$, we get $w-A v \in N_{C}(v)$.

From $v_{n} \in C$, we have

$$
\left\langle v-v_{n}, w-A v\right\rangle \geq 0 .
$$

On the other hand, since $v_{n}=\Pi_{C} J^{-1}\left(J x_{n}-\lambda_{n} A x_{n}\right)$. Then, by Lemma 2.5, we have

$$
\left\langle v-v_{n}, J v_{n}-\left(J x_{n}-\lambda_{n} A x_{n}\right)\right\rangle \geq 0,
$$

and thus

$$
\left\langle v-v_{n}, \frac{J x_{n}-J v_{n}}{\lambda_{n}}-A x_{n}\right\rangle \leq 0 .
$$


It follows from (3.48), (3.49) and $A$ is monotone and $\frac{1}{\alpha}$-Lipschitz continuous that

$$
\begin{aligned}
\left\langle v-v_{n}, w\right\rangle & \geq\left\langle v-v_{n}, A v\right\rangle \\
& \geq\left\langle v-v_{n}, A v\right\rangle+\left\langle v-v_{n}, \frac{J x_{n}-J v_{n}}{\lambda_{n}}-A x_{n}\right\rangle \\
& =\left\langle v-v_{n}, A v-A x_{n}\right\rangle+\left\langle v-z v_{n}, \frac{J x_{n}-J v_{n}}{\lambda_{n}}\right\rangle \\
& =\left\langle v-v_{n}, A v-A v_{n}\right\rangle+\left\langle v-v_{n}, A v_{n}-A x_{n}\right\rangle+\left\langle v-v_{n}, \frac{J x_{n}-J v_{n}}{\lambda_{n}}\right\rangle \\
& \geq-\left\|v-v_{n}\right\| \frac{\left\|v_{n}-x_{n}\right\|}{\alpha}-\left\|v-v_{n}\right\| \frac{\left\|J x_{n}-J v_{n}\right\|}{a} \\
& \geq-H\left(\frac{\left\|v_{n}-x_{n}\right\|}{\alpha}+\frac{\left\|J x_{n}-J v_{n}\right\|}{a}\right),
\end{aligned}
$$

where $H=\sup _{n \geq 1}\left\|v-v_{n}\right\|$. Take the limit as $n i \rightarrow \infty$, (3.31) and (3.32), we obtain $\langle v$ - $p, w\rangle \geq 0$. By the maximality of $B$ we have $p \in B^{-1} 0$, that is $p \in \operatorname{VI}(A, C)$. Hence, from (a), (b) and (c), we obtain $p \in F$.

Finally, we show that $p=\Pi_{F} x_{0}$. From $x_{n}=\Pi_{C_{n}} x_{0}$, we have $\left\langle J x_{0}-J x_{n}, x_{n}-z\right\rangle \geq 0, \forall z \in$ $C_{n}$. Since $F \subset C_{n}$, we also have

$$
\left\langle J x_{0}-J x_{n}, x_{n}-y\right\rangle \geq 0, \quad \forall y \in F .
$$

Taking limit $n \rightarrow \infty$, we obtain

$$
\left\langle J x_{0}-J p, p-y\right\rangle \geq 0, \quad \forall y \in F .
$$

By Lemma 2.5, we can conclude that $p=\Pi_{F} x_{0}$ and $x_{n} \rightarrow p$ as $n \rightarrow \infty$. This completes the proof.

If $S_{i}=S$ for each $i \in \mathbb{N}$, then Theorem 3.1 is reduced to the following corollary.

Corollary 3.2. Let $C$ be a nonempty closed and convex subset of a 2-uniformly convex and uniformly smooth Banach space E. For each $j=1,2, \ldots, m$ let $f_{j}$ be a bifunction from $C \times C$ to $\mathbb{R}$ which satisfies conditions (A1)-(A4), $B_{j}: C \rightarrow E^{*}$ be a continuous and monotone mapping and $\phi_{j}: C \rightarrow \mathbb{R}$ be a lower semicontinuous and convex function. Let $A$ be an $\alpha$-inverse-strongly monotone mapping of $C$ into $E^{*}$ satisfying $\|A y\| \leq \| A y$ $A u \|, \forall y \in C$ and $u \in V I(A, C) \neq \varnothing$. Let $S: C \rightarrow C$ be a closed L-Lipschitz continuous and quasi- $\varphi$-asymptotically nonexpansive mappings with a sequence $\left\{k_{n}\right\} \subset[1, \infty), k_{n}$ $\rightarrow 1$ such that $F:=F(S) \cap\left(\cap_{j=1}^{m} \operatorname{GMEP}\left(f_{j}, B_{j}, \varphi_{j}\right)\right) \cap \operatorname{VI}(A, C)$ is a nonempty and bounded subset in C. For an initial point $x_{0} \in E$ with $x_{1}=\Pi_{C_{1}} x_{0}$ and $C_{1}=C$, we define the sequence $\left\{x_{n}\right\}$ as follows:

$$
\left\{\begin{array}{l}
v_{n}=\Pi_{C} J^{-1}\left(J x_{n}-\lambda_{n} A x_{n}\right), \\
z_{n}=J^{-1}\left(\alpha_{n} J x_{n}+\left(1-\alpha_{n}\right) J S^{n} v_{n}\right), \\
y_{n}=J^{-1}\left(\beta_{n} J x_{n}+\left(1-\beta_{n}\right) J z_{n}\right), \\
u_{n}=T_{r_{m, n}}^{Q_{m}} T_{r_{m-1, n}}^{Q_{m-1}} \cdots T_{r_{2}, n}^{Q_{2}} T_{r_{1, n}}^{Q_{1}} y_{n}, \\
C_{n+1}=\left\{z \in C_{n}: \phi\left(z, u_{n}\right) \leq \phi\left(z, x_{n}\right)+\theta_{n}\right\}, \\
x_{n+1}=\prod_{C_{n+1}} x_{0}, \quad \forall n \geq 1,
\end{array}\right.
$$

where $\theta_{n}=\sup _{q \in F}\left(k_{n}-1\right) \varphi\left(q, x_{n}\right),\left\{\alpha_{n}\right\},\left\{\beta_{n}\right\}$ are sequences in $[0,1],\left\{r_{j, n}\right\} \subset[d, \infty)$ for some $d>0$ and $\left\{\lambda_{n}\right\} \subset[a, b]$ for some $a, b$ with $0<a<b<c^{2} \alpha / 2$, where $\frac{1}{c} c$ is the 2uniformly convexity constant of $E$. If $\lim _{\inf _{n \rightarrow \infty}}\left(1-\beta_{n}\right)>0$ and $\lim \inf _{n \rightarrow \infty}\left(1-\alpha_{n}\right)>0$, then $\left\{x_{n}\right\}$ converges strongly to $p \in F$, where $p=\Pi_{F} x_{0}$. 
For a special case that $i=1,2$, we can obtain the following results on a pair of quasi-asymptotically nonexpansive mappings immediately from Theorem 3.1.

Corollary 3.3. Let $C$ be a nonempty closed and convex subset of a 2-uniformly convex and uniformly smooth Banach space E. For each $j=1,2, \ldots, m$ let $f_{j}$ be a bifunction from $C \times C$ to $\mathbb{R}$ which satisfies conditions (A1)-(A4), $B_{j}: C \rightarrow E^{*}$ be a continuous and monotone mapping and $\phi_{j}: C \rightarrow \mathbb{R}$ be a lower semicontinuous and convex function. Let $A$ be an $\alpha$-inversestrongly monotone mapping of $C$ into $E^{*}$ satisfying $\|A y\| \leq \| A y$ $A u \|, \forall y \in C$ and $u \in V I(A, C) \neq \varnothing$. Let $S, T: C \rightarrow C$ be two closed quasi- $\varphi$-asymptotically nonexpansive mappings and $L_{S}, L_{T}$-Lipschitz continuous, respectively with a sequence $\left\{k_{n}\right\} \subset\left[\begin{array}{lllll}1, & \infty\end{array}\right), \quad k_{n} \rightarrow \quad 1 \quad$ such that $F:=F(S) \cap F(T) \cap\left(\cap_{j=1}^{m} \operatorname{GMEP}\left(f_{j}, B_{j}, \varphi_{j}\right)\right) \cap \operatorname{VI}(A, C)$ is a nonempty and bounded subset in C. For an initial point $x_{0} \in E$ with $x_{1}=\Pi_{C_{1}} x_{0}$ and $C_{1}=C$, we define the sequence $\left\{x_{n}\right\}$ as follows:

$$
\left\{\begin{array}{l}
v_{n}=\Pi_{C} J^{-1}\left(J x_{n}-\lambda_{n} A x_{n}\right) \\
z_{n}=J^{-1}\left(\alpha_{n} J x_{n}+\beta_{n} J S^{n} v_{n}+\gamma_{n} J T^{n} v_{n}\right) \\
y_{n}=J^{-1}\left(\delta_{n} J x_{n}+\left(1-\delta_{n}\right) J z_{n}\right) \\
u_{n}=T_{r_{m, n}}^{Q_{m}} T_{r_{m-1, n}}^{Q_{m-1}} \cdots T_{r_{2, n}}^{Q_{2}} T_{r_{1, n}}^{Q_{1}} y_{n} \\
C_{n+1}=\left\{z \in C_{n}: \phi\left(z, u_{n}\right) \leq \phi\left(z, x_{n}\right)+\theta_{n}\right\} \\
x_{n+1}=\prod_{C_{n+1}} x_{0}, \quad \forall n \geq 0
\end{array}\right.
$$

where $\theta_{n}=\sup _{q \in F}\left(k_{n}-1\right) \varphi\left(q, x_{n}\right),\left\{\alpha_{n}\right\},\left\{\beta_{n}\right\},\left\{\gamma_{n}\right\}$ and $\left\{\delta_{n}\right\}$ are sequences in $[0,1],\left\{r_{j}\right.$, $\left.{ }_{n}\right\} \subset[d, \infty)$ for some $d>0$ and $\left\{\lambda_{n}\right\} \subset[a, b]$ for some $a, b$ with $0<a<b<c^{2} \alpha / 2$, where $\frac{1}{c}$ is the 2-uniformly convexity constant of $E$. If $\alpha_{n}+\beta_{n}+\gamma_{n}=1$ for all $n \geq 0$ and $\lim _{\inf _{n \rightarrow \infty}} \alpha_{n} \beta_{n}>0, \liminf _{n \rightarrow \infty} \alpha_{n} \gamma_{n}>0, \lim _{\inf _{n \rightarrow \infty}} \beta_{n} \gamma_{n}>0$ and $\lim _{\inf _{n \rightarrow \infty}}\left(1-\delta_{n}\right)$ $>0$, then $\left\{x_{n}\right\}$ converges strongly to $p \in F$, where $p=\Pi_{F} x_{0}$.

Corollary 3.4. Let $C$ be a nonempty closed and convex subset of a 2-uniformly convex and uniformly smooth Banach space E. For each $j=1,2, \ldots, m$ let $f_{j}$ be a bifunction from $C \times C$ to $\mathbb{R}$ which satisfies conditions (A1)-(A4), $B_{j}: C \rightarrow E^{*}$ be a continuous and monotone mapping and $\phi_{j}: C \rightarrow \mathbb{R}$ be a lower semicontinuous and convex function. Let $A$ be an $\alpha$-inverse-strongly monotone mapping of $C$ into $E^{*}$ satisfying $\|A y\| \leq \| A y$ $A u \|, \forall y \in C$ and $u \in V I(A, C) \neq \varnothing$. Let $\left\{S_{i}\right\}_{i=1}^{\infty}: C \rightarrow$ Cbe an infinite family of closed quasi- $\varphi$ - nonexpansive mappings such that $F:=\cap_{i=1}^{\infty} F\left(S_{i}\right) \cap\left(\cap_{j=1}^{m} \operatorname{GMEP}\left(f_{j}, B_{j}, \varphi_{j}\right)\right) \cap \operatorname{VI}(A, C) \neq \emptyset$.For an initial point $x_{0} \in E$ with $x_{1}=\Pi_{C_{1}} x_{0}$ and $C_{1}=C$, we define the sequence $\left\{x_{n}\right\}$ as follows:

$$
\left\{\begin{array}{l}
v_{n}=\Pi_{C} J^{-1}\left(J x_{n}-\lambda_{n} A x_{n}\right), \\
z_{n}=J^{-1}\left(\alpha_{n, 0} J x_{n}+\sum_{i=1}^{\infty} \alpha_{n, i} J S_{i} v_{n}\right), \\
y_{n}=J^{-1}\left(\beta_{n} J x_{n}+\left(1-\beta_{n}\right) J z_{n}\right), \\
u_{n}=T_{r_{m, n}}^{Q_{m}} T_{r_{m-1, n}}^{Q_{m-1}} \cdots T_{r_{2, n}}^{Q_{2}} T_{r_{1, n}}^{Q_{1}} y_{n}, \\
C_{n+1}=\left\{z \in C_{n}: \phi\left(z, u_{n}\right) \leq \phi\left(z, x_{n}\right),\right. \\
x_{n+1}=\Pi_{C_{n+1}} x_{0}, \quad \forall n \geq 0,
\end{array}\right.
$$

where $\left\{\alpha_{n}, i\right\}$ and $\left\{\beta_{n}\right\}$ are sequences in $[0,1],\left\{r_{j}, n\right\} \subset[d, \infty)$ for some $d>0$ and $\left\{\lambda_{n}\right\} \subset$ $[a, b]$ for some $a, b$ with $0<a<b<c^{2} \alpha / 2$, where $\frac{1}{c} i s$ the 2-uniformly convexity constant of $E$. If $\sum_{i=0}^{\infty} \alpha_{n, i}=1$ for all $n \geq 0, \lim \inf _{n \rightarrow \infty}\left(1-\beta_{n}\right)>0$ and $\lim _{\inf _{n \rightarrow \infty}} \alpha_{n, 0} \alpha_{n, i}$ $>0$ for all $i \geq 1$, then $\left\{x_{n}\right\}$ converges strongly to $p \in F$, where $p=\Pi_{F} x_{0}$.

Proof. Since $\left\{S_{i}\right\}_{i=1}^{\infty}: C \rightarrow C$ is an infinite family of closed quasi- $\varphi$-nonexpansive mappings, it is an infinite family of closed and uniformly quasi- $\varphi$-asymptotically 
nonexpansive mappings with sequence $k_{n}=1$. Hence, the conditions appearing in Theorem 3.1 $F$ is a bounded subset in $C$ and for each $i \geq 1, S_{i}$ is uniformly $L_{i}$-Lipschitz continuous are of no use here. By virtue of the closeness of mapping $S_{i}$ for each $i \geq 1$, it yields that $p \in F\left(S_{i}\right)$ for each $i \geq 1$, that is, $p \in \cap_{i=1}^{\infty} F\left(S_{i}\right)$. Therefore, all conditions in Theorem 3.1 are satisfied. The conclusion of Corollary 3.4 is obtained from Theorem 3.1 immediately.

\section{Deduced theorems}

Corollary 4.1. [[41], Theorem 3.2] Let $C$ be a nonempty closed and convex subset of a 2-uniformly convex and uniformly smooth Banach space $E$. Let $f$ be a bifunction from $C$ $\times C$ to $\mathbb{R}$ satisfying (A1)-(A4) and $\phi: C \rightarrow \mathbb{R}$ is convex and lower semicontinuous. Let $A$ be an $\alpha$-inverse-strongly monotone mapping of $C$ into $E^{*}$ satisfying $\|A y\| \leq \| A y$ $A u \|, \forall y \in C$ and $u \in V I(A, C) \neq \varnothing$. Let $\left\{S_{i}\right\}_{i=1}^{N}: C \rightarrow$ Cbe a finite family of closed quasi- $\varphi$ - nonexpansive mappings such that $F:=\cap_{i=1}^{N} F\left(S_{i}\right) \cap \operatorname{GMEP}(f, B, \varphi) \cap \operatorname{VI}(A, C) \neq \emptyset$. For an initial point $x_{0} \in E$ with $\frac{1}{c}$ and $C_{1}$ $=C$, we define the sequence $\left\{x_{n}\right\}$ as follows:

$$
\left\{\begin{array}{l}
z_{n}=\Pi_{C} J^{-1}\left(J x_{n}-\lambda_{n} A x_{n}\right) \\
y_{n}=J^{-1}\left(\alpha_{0} J x_{n}+\sum_{i=1}^{N} \alpha_{i} J S_{i} z_{n}\right), \\
f\left(u_{n}, y\right)+\left\langle B u_{n}, y-u_{n}\right\rangle+\varphi(\gamma)-\varphi\left(u_{n}\right)+\frac{1}{r_{n}}\left\langle y-u_{n}, J u_{n}-J y_{n}\right\rangle \geq 0, \quad \forall y \in C,(4.1) \\
C_{n+1}=\left\{z \in C_{n}: \phi\left(z, u_{n}\right) \leq \phi\left(z, x_{n}\right),\right. \\
x_{n+1}=\prod_{C_{n+1}} x_{0}, \quad \forall n \geq 0,
\end{array}\right.
$$

where $\left\{\alpha_{i}\right\}$ is sequence in $[0,1],\left\{r_{n}\right\} \subset[d, \infty)$ for some $d>0$ and $\left\{\lambda_{n}\right\} \subset[a, b]$ for some $a, b$ with $0<a<b<c^{2} \alpha / 2$, where $\frac{1}{c} c$ is the 2-uniformly convexity constant of $E$. If $\alpha_{i} \in$ $(0,1)$ such that $\sum_{i=0}^{N} \alpha_{i}=1$ then $\left\{x_{n}\right\}$ converges strongly to $p \in F$, where $p=\Pi_{F} x_{0}$.

Remark 4.2. Theorems 3.1, Corollaries 3.4 and 4.1 improve and extend the corresponding results of Wattanawitoon and Kumam [14] and Zegeye [41] in the following senses:

- from a solution of the classical equilibrium problem to the generalized mixed equilibrium problem with an infinite family of quasi- $\varphi$-asymptotically mappings;

- for the mappings, we extend the mappings from nonexpansive mappings, relatively quasi-nonexpansive mappings or quasi- $\varphi$-nonexpansive mappings and a finite family of closed relatively quasi-nonexpansive mappings to an infinite family of quasi- $\varphi$-asymptotically nonex-pansive mappings.

Corollary 4.3. Let $C$ be a nonempty closed and convex subset of a uniformly convex and uniformly smooth Banach space $E$. Let $f$ be a bifunction from $C \times C$ to $\mathbb{R}$ satisfying (A1)-(A4) and $\phi: C \rightarrow \mathbb{R}$ is convex and lower semicontinuous. Let $B$ be a continuous monotone mapping of $C$ into $E^{*}$. Let $\left\{S_{i}\right\}_{i=1}^{\infty}: C \rightarrow$ Cbe an infinite family of closed and uniformly quasi- $\varphi$-asymptotically nonexpansive mappings with a sequence $\left\{k_{n}\right\} \subset[1, \infty)$, $k_{n} \rightarrow 1$ and uniformly $L_{i}$-Lipschitz continuous such that $F:=\cap_{i=1}^{\infty} F\left(S_{i}\right) \cap \operatorname{GMEP}(f, B, \varphi)$ is a nonempty and bounded subset in $C$. For an initial point $x_{0} \in E$ with $x_{1}=\Pi_{C_{1}} x_{0}$ and $C_{1}=C$, we define the sequence $\left\{x_{n}\right\}$ as follows: 


$$
\left\{\begin{array}{l}
y_{n}=J^{-1}\left(\alpha_{n, 0} J x_{n}+\sum_{i=1}^{\infty} \alpha_{n, i} J S_{i}^{n} x_{n}\right), \\
f\left(u_{n}, y\right)+\left\langle B u_{n}, y-u_{n}\right\rangle+\varphi(\gamma)-\varphi\left(u_{n}\right)+\frac{1}{r_{n}}\left\langle y-u_{n}, J u_{n}-J y_{n}\right\rangle \geq 0, \quad \forall y \in C, \\
C_{n+1}=\left\{z \in C_{n}: \phi\left(z, u_{n}\right) \leq \phi\left(z, x_{n}\right)+\theta_{n}\right\}, \\
x_{n+1}=\prod_{C_{n+1}} x_{0}, \quad \forall n \geq 0,
\end{array}\right.
$$

where $\theta_{n}=\sup _{q \in F}\left(k_{n}-1\right) \varphi\left(q, x_{n}\right),\left\{\alpha_{n},\right\}$ is sequence in $[0,1],\left\{r_{n}\right\} \subset[a, \infty)$ for some a $>0$. If $\sum_{i=0}^{\infty} \alpha_{n, i}=1$ for all $n \geq 0$ and $\lim _{\inf _{n \rightarrow \infty}} \alpha_{n, 0} \alpha_{n, i}>0$ for all $i \geq 1$, then $\left\{x_{n}\right\}$ converges strongly to $p \in F$, where $p=\Pi_{F} x_{0}$.

Proof. Put $A \equiv 0$ in Theorem 3.1 Then, we get that $z_{n}=x_{n}$. Thus, the method of proof of Theorem 3.1 gives the required assertion without the requirement that $E$ be 2-uniformly convex.

If setting $B \equiv 0$ and $\phi \equiv 0$ in Corollary 4.3, then we have the following corollary.

Corollary 4.4. Let $C$ be a nonempty closed and convex subset of a uniformly convex and uniformly smooth Banach space $E$. Let $f$ be a bifunction from $\mathrm{C} \times \mathrm{C}$ to $\mathbb{R}$ satisfying (A1)-(A4) and $\phi: C \rightarrow \mathbb{R}$ is convex and lower semicontinuous. Let $\left\{S_{i}\right\}_{i=1}^{\infty}: C \rightarrow$ Cbe an infinite family of closed and uniformly quasi- $\varphi$-asymptotically nonexpansive mappings with a sequence $\left\{k_{n}\right\} \subset[1, \infty), k_{n} \rightarrow 1$ and uniformly $L_{i}$-Lipschitz continuous such that $F:=\cap_{i=1}^{\infty} F\left(S_{i}\right) \cap \operatorname{EP}(f)$ is a nonempty and bounded subset in $C$. For an initial point $x_{0}$ $\in E$ with $x_{1}=\Pi_{C_{1}} x_{0}$ and $C_{1}=C$, we define the sequence $\left\{x_{n}\right\}$ as follows:

$$
\left\{\begin{array}{l}
y_{n}=J^{-1}\left(\alpha_{n, 0} J x_{n}+\sum_{i=1}^{\infty} \alpha_{n, i} J S_{i}^{n} x_{n}\right), \\
f\left(u_{n}, y\right)+\frac{1}{r_{n}}\left\langle y-u_{n}, J u_{n}-J y_{n}\right\rangle \geq 0, \quad \forall y \in C, \\
C_{n+1}=\left\{z \in C_{n}: \phi\left(z, u_{n}\right) \leq \phi\left(z, x_{n}\right)+\theta_{n}\right\}, \\
x_{n+1}=\Pi_{C_{n+1}} x_{0}, \quad \forall n \geq 0,
\end{array}\right.
$$

where $\theta_{n}=\sup _{q \in F}\left(k_{n}-1\right) \varphi\left(q, x_{n}\right),\left\{\alpha_{n, i}\right\}$ is sequence in $[0,1],\left\{r_{n}\right\} \subset[a, \infty)$ for some a $>0$. If $\sum_{i=0}^{\infty} \alpha_{n, i}=1$ for all $n \geq 0$ and $\lim _{\inf _{n \rightarrow \infty}} \alpha_{n, 0} \alpha_{n, i}>0$ for all $i \geq 1$, then $\left\{x_{n}\right\}$ converges strongly to $p \in F$, where $p=\Pi_{F} x_{0}$.

Remark 4.5. Corollaries 4.3 and 4.4 improve and extend the corresponding results of Zegeye [41] and Wattanawitoon and Kumam [14] in the sense from a finite family of closed relatively quasi-nonexpansive mappings and closed relatively quasi-nonexpansive mappings to more general than an infinite family of closed and uniformly quasi- $\varphi$ asymptotically nonexpansive mappings.

Remark 4.6. Moreover, Our theorems improve, generalize, unify and extend Qin et al. [9], Zeg-eye et al. [15], Zegeye [41] and Wattanawitoon and Kumam [14,49] and several results recently announced.

\section{Applications}

\subsection{Application to complementarity problems}

Let $K$ be a nonempty, closed convex cone in $E$. We define the polar $K^{*}$ of $K$ as follows:

$$
K^{*}=\left\{\gamma^{*} \in E^{*}:\left\langle x, y^{*}\right\rangle \geq 0, \forall x \in K\right\} .
$$

If $A: K \rightarrow E^{*}$ is an operator, then an element $u \in K$ is called a solution of the complementarity problem [20] if

$$
A u \in K^{*} \quad \text { and } \quad\langle u, A u\rangle=0 .
$$

The set of solutions of the complementarity problem is denoted by $C P(A, K)$. 
Theorem 5.1. Let $K$ be a nonempty closed and convex subset of a 2-uniformly convex and uniformly smooth Banach space E. For each $j=1,2, \ldots, m$ let $f_{j}$ be a bifunction from $C \times C$ to $\mathbb{R}$ which satisfies conditions (A1)-(A4), $B_{j}: C \rightarrow E^{*}$ be a continuous and monotone mapping and $\phi_{j}: C \rightarrow \mathbb{R}$ be a lower semicontinuous and convex function. Let $A$ be an $\alpha$-inverse-strongly monotone mapping of $K$ into $E^{* *}$ satisfying $\|A y\| \leq \| A y$ $A u \|, \forall y \in K$ and $u \in C P(A, K) \neq \varnothing$. Let $\left\{S_{i}\right\}_{i=1}^{\infty}: K \rightarrow K$ be an infinite family of closed uniformly $L_{i}$-Lipschitz continuous and uniformly quasi- $\varphi$-asymptotically nonexpansive mappings with a sequence $\left\{k_{n}\right\} \subset[1, \infty), k_{n} \rightarrow 1$ such that $F:=\cap_{i=1}^{\infty} F\left(S_{i}\right) \cap\left(\cap_{j=1}^{m} \operatorname{GMEP}\left(f_{j}, B_{j}, \varphi_{j}\right)\right) \cap C P(A, K)$ is a nonempty and bounded subset in $K$. For an initial point $x_{0} \in E$ with $x_{1}=\Pi_{C_{1}} x_{0}$ and $K_{1}=K$, we define the sequence $\left\{x_{n}\right\}$ as follows:

$$
\left\{\begin{array}{l}
v_{n}=\Pi_{K} J^{-1}\left(J x_{n}-\lambda_{n} A x_{n}\right), \\
z_{n}=J^{-1}\left(\alpha_{n, 0} J x_{n}+\sum_{i=1}^{\infty} \alpha_{n, i} J S_{i}^{n} v_{n}\right), \\
y_{n}=J^{-1}\left(\beta_{n} J x_{n}+\left(1-\beta_{n}\right) J z_{n}\right), \\
u_{n}=T_{r_{m, n}}^{Q_{m}} T_{r_{m-1, n}}^{Q_{m-1}} \cdots T_{r_{2}, n}^{Q_{2}} T_{r_{1, n}}^{Q_{1}} y_{n}, \\
K_{n+1}=\left\{z \in K_{n}: \phi\left(z, u_{n}\right) \leq \phi\left(z, x_{n}\right)+\theta_{n}\right\}, \\
x_{n+1}=\prod_{K_{n+1}} x_{0}, \quad \forall n \geq 0,
\end{array}\right.
$$

where $J$ is the duality mapping on $E, \theta_{n}=\sup _{q \in F}\left(k_{n}-1\right) \varphi\left(q, x_{n}\right)$, for each $i \geq 0,\left\{\alpha_{n}\right.$, $i\}$ and $\left\{\beta_{n}\right\}$ are sequences in $[0,1],\left\{r_{j, n}\right\} \subset[d, \infty)$ for some $d>0$ and $\left\{\lambda_{n}\right\} \subset[a, b]$ for some $a, b$ with $0<a<b<c^{2} \alpha / 2$, where $\frac{1}{c}$ is the 2-uniformly convexity constant of $E$. If $\sum_{i=0}^{\infty} \alpha_{n, i}=1$ for all $n \geq 0, \lim \inf _{n \rightarrow \infty}\left(1-\beta_{n}\right)>0$ and $\lim _{\inf _{n \rightarrow \infty}} \alpha_{n, 0} \alpha_{n, i}>0$ for all $i$ $\geq 1$, then $\left\{x_{n}\right\}$ converges strongly to $p \in F$, where $p=\Pi_{F} x_{0}$.

Proof. As in the proof of Takahashi in [[20], Lemma 7.11], we get that $\operatorname{VI}(A, K)=C P$ $(A, K)$. So, we obtain the result. $\square$

\subsection{Application to zero points}

Next, we consider the problem of finding a zero point of an inverse-strongly monotone operator of $E$ into $E^{*}$. Assume that $A$ satisfies the conditions:

(C1) $A$ is $\alpha$-inverse-strongly monotone,

(C2) $A^{-1} 0=\{u \in E: A u=0\} \neq \varnothing$.

Theorem 5.2. Let $C$ be a nonempty closed and convex subset of a 2-uniformly convex and uniformly smooth Banach space E. For each $j=1,2, \ldots, m$ let $f_{j}$ be a bifunction from $C \times C$ to $\mathrm{R}$ which satisfies conditions (A1)-(A4), $B_{j}: C \rightarrow E^{*}$ be a continuous and monotone mapping and $\phi_{j}: C \rightarrow \mathbb{R}$ be a lower semicontinuous and convex function. Let $A$ be an operator of E into $E^{*}$ satisfying (C1) and (C2). Let $\left\{S_{i}\right\}_{i=1}^{\infty}: C \rightarrow$ Cbe an infinite family of closed uniformly $L_{i^{-}}$Lipschitz continuous and uniformly quasi- $\varphi$-asymptotically nonexpansive mappings with a sequence $\left\{k_{n}\right\} \subset[1, \infty), k_{n} \rightarrow 1$ such that

$$
F:=\cap_{i=1}^{\infty} F\left(S_{i}\right) \cap\left(\cap_{j=1}^{m} \operatorname{GMEP}\left(f_{j}, B_{j}, \varphi_{j}\right)\right) \cap A^{-1} 0
$$

is a nonempty and bounded subset in C: For an initial point $x_{0} \in E$ with $x_{1}=\Pi_{C_{1}} x_{0}$ and $C_{1}=C$, we define the sequence $\left\{x_{n}\right\}$ as follows:

$$
\left\{\begin{array}{l}
v_{n}=\Pi_{C} J^{-1}\left(J x_{n}-\lambda_{n} A x_{n}\right), \\
z_{n}=J^{-1}\left(\alpha_{n, 0} J x_{n}+\sum_{i=1}^{\infty} \alpha_{n, i} J S_{i}^{n} v_{n}\right), \\
y_{n}=J^{-1}\left(\beta_{n} J x_{n}+\left(1-\beta_{n}\right) J z_{n}\right), \\
u_{n}=T_{r_{m, n}}^{Q_{m}} T_{r_{m-1, n}}^{Q_{m-1}} \cdots T_{r_{2, n}}^{Q_{2}} T_{r_{1, n}}^{Q_{1}} y_{n}, \\
C_{n+1}=\left\{z \in C_{n}: \phi\left(z, u_{n}\right) \leq \phi\left(z, x_{n}\right)+\theta_{n}\right\}, \\
x_{n+1}=\Pi_{C_{n+1}} x_{0}, \quad \forall n \geq 0,
\end{array}\right.
$$


where $J$ is the duality mapping on $E, \theta_{n}=\sup _{q \in F}(k n-1) \varphi\left(q, x_{n}\right)$, for each $i \geq 0,\left\{\alpha_{n}\right.$, i) and $\left\{\beta_{n}\right\}$ are sequences in $[0,1],\left\{r_{j, n}\right] \subset[d, \infty)$ for some $d>0$ and $\left\{\lambda_{n}\right\} \subset[a, b]$ for some $a, b$ with $0<a<b<c^{2} \alpha / 2$, where $\frac{1}{c}$ is the 2-uniformly convexity constant of $E$. If $\sum_{i=0}^{\infty} \alpha_{n, i}=1$ for all $n \geq 0, \lim \inf _{n \rightarrow \infty}\left(1-\beta_{n}\right)>0$ and $\lim _{\inf _{n \rightarrow \infty}} \alpha_{n, 0} \alpha_{n, i}>0$ for all $i$ $\geq 1$, then $\left\{x_{n}\right\}$ converges strongly to $p \in F$, where $p=\Pi_{F} x_{0}$.

Proof. Setting $C=E$ in Corollary 3.4, we also get $\Pi_{E}=I$. We also have $\operatorname{VI}(A, C)=\mathrm{VI}$ $(A, E)\{x \in E: A x=0\} \neq \varnothing$ and then the condition $\|A y\| \leq\|A y-A u\|$ holds for all $y$ $\in E$ and $u \in A^{-1} 0$. So, we obtain the result.

\subsection{Application to Hilbert spaces}

If $E=H$, a Hilbert space, then $E$ is 2-uniformly convex (we can choose $c=1$ ) and uniformly smooth real Banach space and closed relatively quasi-nonexpansive map reduces to closed quasi-nonexpansive map. Moreover, $J=I$, identity operator on $H$ and $\Pi_{C}=P C$, projection mapping from $H$ into $C$ : Thus, the following corollaries hold.

Theorem 5.3. Let $C$ be a nonempty closed and convex subset of a Hilbert space $H$. For each $j=1,2, \ldots, m$ let $f_{j}$ be a bifunction from $C \times C$ to $\mathbb{R}$ which satisfies conditions (A1)-(A4), $\mathrm{B}_{j}: C \rightarrow E^{*}$ be a continuous and monotone mapping and $\phi_{j}: C \rightarrow \mathbb{R}$ be a lower semicontinuous and convex function. Let $A$ be an $\alpha$-inverse-strongly monotone mapping of $C$ into $H$ satisfying $\|A y\| \leq\|A y-A u\|, \forall y \in C$ and $u \in V I(A, C) \neq \varnothing$. Let $\left\{S_{i}\right\}_{i=1}^{\infty}: C \rightarrow$ Cbe an infinite family of closed and uniformly quasi- $\varphi$-asymptotically nonexpansive mappings with a sequence $\left\{k_{n}\right\} \subset[1, \infty), k_{n} \rightarrow 1$ and uniformly $L_{i^{-}}$ Lipschitz continuous such that $F:=\cap_{i=1}^{\infty} F\left(S_{i}\right) \cap\left(\cap_{j=1}^{m} \operatorname{GMEP}\left(f_{j}, B_{j}, \varphi_{j}\right)\right) \cap \operatorname{VI}(A, C)$ is a nonempty and bounded subset in $C$. For an initial point $x_{0} \in H$ with $x_{1}=P_{C_{1}} x_{0}$ and $C_{1}=C$, we define the sequence $\left\{x_{n}\right\}$ as follows:

$$
\left\{\begin{array}{l}
z_{n}=P_{C}\left(x_{n}-\lambda_{n} A x_{n}\right), \\
y_{n}=\alpha_{n, 0} x_{n}+\sum_{i=1}^{\infty} \alpha_{n, i} S_{i}^{n} z_{n}, \\
u_{n}=T_{r_{m, n}}^{Q_{m}} T_{r_{m-1, n}}^{Q_{m-1}} \cdots T_{r_{2, n}}^{Q_{2}} T_{r_{1, n}}^{Q_{1}} y_{n}, \\
C_{n+1}=\left\{z \in C_{n}:\left\|z-u_{n}\right\| \leq\left\|z-x_{n}\right\|+\theta_{n}\right\}, \\
x_{n+1}=P_{C_{n+1}} x_{0}, \quad \forall n \geq 0,
\end{array}\right.
$$

where $\theta_{n}=\sup _{q L F}\left(k_{n}-1\right)\left\|\mid q-x_{n}\right\|,\left\{\alpha_{n}, i\right\}$ is sequence in $[0,1],\left\{r_{j, n}\right\} \subset[a, \infty)$ for some $a>0$ and $\left\{\lambda_{n}\right\} \subset[a, b]$ for some $a ; b$ with $0<a<b<\alpha / 2$. If $\sum_{i=0}^{\infty} \alpha_{n, i}=1$ for all $n \geq 0$ and $\lim _{\inf _{n \rightarrow \infty}} \alpha_{n, 0} \alpha_{n, i}>0$ for all $i \geq 1$, then $\left\{x_{n}\right\}$ converges strongly to $p \in F$, where $p$ $=\Pi_{F} x_{0}$.

Remark 5.4. Theorem 5.3 improves and extends the Corollary 3.7 in Zegeye [41] in the aspect for the mappings, and we extend the mappings from a finite family of closed relatively quasi-nonexpansive mappings to a more general infinite family of closed and uniformly quasi- $\varphi$-asymptotically nonexpansive mappings.

\section{Competing interests}

The authors declare that they have no competing interests.

\section{Authors' contributions}

All authors contribute equally and significantly in this research work. All authors read and approved the final manuscript. 


\section{Acknowledgements}

This research was supported by grant from under the program Strategic Scholarships for Frontier Research Network for the Join Ph.D. Program Thai Doctoral degree from the Office of the Higher Education Commission, Thailand. Also, Siwaporn Saewan was supported by the King Mongkuts Diamond scholarship for Ph.D. program at King Mongkuts University of Technology Thonburi (KMUTT) (under project NRU-CSEC No.54000267). Moreover, this work was supported by the Higher Education Research Promotion and National Research University Project of Thailand, Office of the Higher Education Commission and Poom Kumam was supported by the Higher Education Commission, the Thailand Research Fund and the King Mongkut's University of Technology Thonburi (Grant No.MRG5380044). Finally, the authors are very grateful to the referees for their careful reading, comments and suggestions, which improved the presentation of this article.

\section{Received: 21 March 2011 Accepted: 15 August 2011 Published: 15 August 2011}

\section{References}

1. Blum, E, Oettli, W: From optimization and variational inequalities to equilibrium problems. Math Student. 63, 123-145 (1994)

2. Combettes, PL, Hirstoaga, SA: Equilibrium programming in Hilbert spaces. J Nonlinear Convex Anal. 6, 117-136 (2005)

3. Jaiboon, C, Kumam, P: A general iterative method for solving equilibrium problems, variational inequality problems and fixed point problems of an infinite family of nonexpansive mappings. J Appl Math Comput. 34(1-2):407-439 (2010). doi:10.1007/s12190-009-0330-x

4. Katchang, P, Kumam, P: A new iterative algorithm of solution for equilibrium problems, variational inequalities and fixed point problems in a Hilbert space. J Appl Math Comput. 32, 19-38 (2010). doi:10.1007/s12190-009-0230-0

5. Kumam, P: A new hybrid iterative method for solution of equilibrium problems and fixed point problems for an inverse strongly monotone operator and a nonexpansive mapping. J Appl Math Comput. 29, 263-280 (2009). doi:10.1007/ s12190-008-0129-1

6. Moudafi, A: Second-order differential proximal methods for equilibrium problems. J Inequal Pure Appl Math. 4, (art. 18) (2003)

7. Qin, $\mathrm{X}$, Cho, YJ, Kang, SM: Convergence theorems of common elements for equilibrium problems and fixed point problems in Banach spaces. J Comput Appl Math. 225, 20-30 (2009). doi:10.1016/j.cam.2008.06.011

8. Qin, X, Cho, SY, Kang, SM: Strong convergence of shrinking projection methods for quasi- $\varphi$-nonexpansive mappings and equilibrium problems. J Comput Appl Math. 234, 750-760 (2010). doi:10.1016/j.cam.2010.01.015

9. Qin, X, Cho, SY, Kang, SM: On hybrid projection methods for asymptotically quasi- $\varphi$-nonexpansive mappings. Appl Math Comput. 215, 3874-3883 (2010). doi:10.1016/j.amc.2009.11.031

10. Saewan, S, Kumam, P: A hybrid iterative scheme for a maximal monotone operator and two countable families of relatively quasi-nonexpansive mappings for generalized mixed equilibrium and variational inequality problems. Abstr Appl Anal 2010, 31 (2010). Article ID 123027

11. Saewan, S, Kumam, P: The shrinking projection method for solving generalized equilibrium problem and common fixed points for asymptotically quasi- $\varphi$-nonexpansive mappings. Fixed Point Theory Appl. 2011, 9 (2011). doi:10.1186/16871812-2011-9

12. Saewan, S, Kumam, P: Strong convergence theorems for countable families of uniformly quasi-phi-asymptotically nonexpansive mappings and a system of generalized mixed equilibrium problems. Abstr Appl Anal 2011, 27 (2011). Article ID 701675

13. Saewan, S, Kumam, P: A modified hybrid projection method for solving generalized mixed equilibrium problems and fixed point problems in Banach spaces. Comput Math Appl. 62, 1723-1735 (2011). doi:10.1016/j.camwa.2011.06.014

14. Wattanawitoon, K, Kumam, P: A strong convergence theorem by a new hybrid projection algorithm for fixed point problems and equilibrium problems of two relatively quasi-nonexpansive mappings. Nonlinear Anal Hybrid Syst. 3(1):11-20 (2009). doi:10.1016/j.nahs.2008.10.002

15. Zegeye, H, Ofoedu, EU, Shahzad, N: Convergence theorems for equilibrium problem, variational inequality problem and countably infinite relatively quasi-nonexpansive mappings. Appl Math Comput. 216, 3439-3449 (2010). doi:10.1016/j. amc.2010.02.054

16. Alber, Yl: Metric and generalized projection operators in Banach spaces: properties and applications. In: Kartsatos AG (ed.) Theory and Applications of Nonlinear Operators of Accretive and Monotone Type. pp. 15-50. Marcel Dekker, New York (1996)

17. Alber, Yl, Reich, S: An iterative method for solving a class of nonlinear operator equations in Banach spaces. Panamer Math J. 4, 39-54 (1994)

18. Cioranescu, I: Geometry of Banach Spaces. Duality Mappings and Nonlinear Problems. Kluwer, Dordrecht (1990)

19. Kamimura, S, Takahashi, W: Strong convergence of a proximal-type algorithm in a Banach space. SIAM J Optim. 13, 938-945 (2002). doi:10.1137/S105262340139611X

20. Takahashi, W: Nonlinear Functional Analysis. Yokohama-Publishers, Japan (2000)

21. Reich, S: A weak convergence theorem for the alternating method with Bregman distance. In: Kartsatos AG (ed.) Theory and Applications of Nonlinear Operators of Accretive and Monotone Type. pp. 313-318. Marcel Dekker, New York (1996)

22. Nilsrakoo, W, Saejung, S: Strong convergence to common fixed points of countable relatively quasi-nonexpansive mappings. Fixed Point Theory Appl 2008, 19 (2008). Article ID 312454

23. Su, Y, Wang, D, Shang, M: Strong convergence of monotone hybrid algorithm for hemi-relatively nonexpansive mappings. Fixed Point Theory Appl 2008, 8 (2008). Article ID 284613

24. Zegeye, $\mathrm{H}$, Shahzad, N: Strong convergence for monotone mappings and relatively weak non-expansive mappings. Nonlinear Anal. 70, 2707-2716 (2009). doi:10.1016/j.na.2008.03.058

25. Butnariu, D, Reich, S, Zaslavski, AJ: Asymptotic behavior of relatively nonexpansive operators in Banach spaces. J Appl Anal. 7, 151-174 (2001). doi:10.1515/JAA.2001.151 
26. Butnariu, D, Reich, S, Zaslavski, AJ: Weak convergence of orbits of nonlinear operators in reflexive Banach spaces. Numer Funct Anal Optim. 24, 489-508 (2003). doi:10.1081/NFA-120023869

27. Censor, Y, Reich, S: Iterations of paracontractions and firmly nonexpansive operators with applications to feasibility and optimization. Optimization. 37, 323-339 (1996). doi:10.1080/02331939608844225

28. Matsushita, S, Takahashi, W: A strong convergence theorem for relatively nonexpansive mappings in a Banach space. J Approx Theory. 134, 257-266 (2005). doi:10.1016/j.jat.2005.02.007

29. Saewan, S, Kumam, P, Wattanawitoon, K: Convergence theorem based on a new hybrid projection method for finding a common solution of generalized equilibrium and variational inequality problems in Banach spaces. Abstr Appl Anal 2010, 26 (2010). Article ID 734126

30. Chang, SS, Kim, JK, Wang, XR: Modified block iterative algorithm for solving convex feasibility problems in Banach spaces. J Inequal Appl 2010, 14 (2010). Article ID 869684

31. Matsushita, S, Takahashi, W: Weak and strong convergence theorems for relatively nonexpan-sive mappings in Banach spaces. Fixed Point Theory Appl. 2004, 37-47 (2004). doi:10.1155/S1687182004310089

32. liduka, H, Takahashi, W: Weak convergence of a projection algorithm for variational inequalities in a Banach space. J Math Anal Appl. 339, 668-679 (2008). doi:10.1016/j.jmaa.2007.07.019

33. Takahashi, W, Zembayashi, K: Strong and weak convergence theorems for equilibrium problems and relatively nonexpansive mappings in Banach spaces. Nonlinear Anal. 70, 45-57 (2009). doi:10.1016/j.na.2007.11.031

34. Takahashi, W, Zembayashi, K: Strong convergence theorem by a new hybrid method for equilibrium problems and relatively nonexpansive mappings. Fixed Point Theory Appl 2008, 11 (2008). Article ID 528476

35. Cholamjiak, P: A hybrid iterative scheme for equilibrium problems, variational inequality problems and fixed point problems in Banach spaces. Fixed Point Theory Appl 2009, 19 (2009). Article ID 312454

36. Cholamjiak, W, Suantai, S: Convergence analysis for a system of equilibrium problems and a countable family of relatively quasi-nonexpansive mappings in Banach spaces. Abstr Appl Anal 2010, 17 (2010). Article ID 141376

37. Kohsaka, F, Takahashi, W: Block iterative methods for a finite family of relatively nonex-pansive mappings in Banach spaces. Fixed Point Theory Appl 2007, 18 (2007). Article ID 21972

38. Kikkawa, M, Takahashi, W: Approximating fixed points of nonexpansive mappings by the block iterative method in Banach spaces. Int J Comput Numer Anal Appl. 5(1):59-66 (2004)

39. Plubtieng, S, Ungchittrakool, K: Hybrid iterative methods for convex feasibility problems and fixed point problems of relatively nonexpansive mappings in Banach spaces. Fixed Point Theory Appl 2008, 19 (2008). Article ID 583082

40. Saewan, S, Kumam, P: Modified hybrid block iterative algorithm for convex feasibility problems and generalized equilibrium problems for uniformly quasi- $\varphi$-asymptotically nonexpansive mappings. Abstr Appl Anal 2010, 22 (2010). Article ID 357120

41. Zegeye, $\mathrm{H}$ : A hybrid iteration scheme for equilibrium problems, variational inequality problems and common fixed point problems in Banach spaces. Nonlinear Anal. 72, 2136-2146 (2010). doi:10.1016/.jna.2009.10.014

42. Ball, K, Carlen, EA, Lieb, EH: Sharp uniform convexity and smoothness inequalities for trace norm. Invent Math. 26, 137-150 (1994)

43. Takahashi, Y, Hashimoto, K, Kato, M: On sharp uniform convexity, smoothness, and strong type, cotype inequalities. J Nonlinear Convex Anal. 3, 267-281 (2002)

44. Beauzamy, B: Introduction to Banach Spaces and their Geometry. North-Holland, Amsterdam, 2 (1985)

45. Xu, HK: Inequalities in Banach spaces with applications. Nonlinear Anal. 16, 1127-1138 (1991). doi:10.1016/0362-546X(91) $90200-K$

46. Zalinescu, C: On uniformly convex functions. J Math Anal Appl. 95, 344-374 (1983). doi:10.1016/0022-247X(83)90112-9

47. Rockafellar, RT: On the maximality of sums of nonlinear monotone operators. Trans Am Math Soc. 149, 75-88 (1970). doi:10.1090/S0002-9947-1970-0282272-5

48. Zhang, S: Generalized mixed equilibrium problem in Banach spaces. Appl Math Mech -Engl Ed. 30, 1105-1112 (2009). doi:10.1007/s10483-009-0904-6

49. Wattanawitoon, K, Kumam, P: Generalized mixed equilibrium problems for maximal monotone operators and two relatively quasi-nonexpansive mappings. Thai J Math. 9(1):165-189 (2011)

doi:10.1186/1687-1812-2011-35

Cite this article as: Saewan and Kumam: A new modified block iterative algorithm for uniformly quasi- $\varphi$ asymptotically nonexpansive mappings and a system of generalized mixed equilibrium problems. Fixed Point

Theory and Applications 2011 2011:35.

\section{Submit your manuscript to a SpringerOpen ${ }^{\circ}$ journal and benefit from:}

- Convenient online submission

- Rigorous peer review

- Immediate publication on acceptance

- Open access: articles freely available online

- High visibility within the field

- Retaining the copyright to your article

Submit your next manuscript at $\boldsymbol{s p r i n g e r o p e n . c o m ~}$ 